\title{
The membrane fouling simulator: development, application, and early-warning of biofouling in RO treatment
}

\author{
Lan Hee Kim ${ }^{\mathrm{a}, t, *}$, Maria Nava-Ocampo ${ }^{\mathrm{a}, \mathrm{t}}$, Mark C.M. van Loosdrecht ${ }^{\mathrm{b}}$, \\ Joop C. Kruithof ${ }^{c}$, Johannes S. Vrouwenveldera,b \\ ${ }^{a}$ King Abdullah University of Science and Technology (KAUST), Water Desalination and Reuse Center (WDRC), \\ Division of Biological and Environmental Science and Engineering (BESE), Thuwal, 23955-6900, Saudi Arabia, \\ Tel.+966 12808 4954; emails: lanhee.kim@kaust.edu.sa (L.H. Kim), maria.navaocampo@kaust.edu.sa (M. Nava-Ocampo), \\ johannes.vrouwenvelder@kaust.edu.sa, j.s.vrouwenvelder@tudelft.nl (J.S.Vrouwenvelder) \\ ${ }^{b}$ Department of Biotechnology, Faculty of Applied Sciences, Delft University of Technology, Van der Maasweg 9, 2629 HZ Delft, \\ The Netherlands, email: m.c.m.vanloosdrecht@tudelft.nl (M.C.M. van Loosdrecht) \\ 'Wetsus European Center of Excellence for Sustainable Water Technology, Oostergoweg 9, 8911 MA Leeuwarden, \\ The Netherlands, email: joop.kruithof@wetsus.nl
}

Received 16 April 2018; Accepted 29 August 2018

\begin{abstract}
A B S T R A C T
The growing demand for fresh water has resulted in increasing use of reverse osmosis (RO) membrane systems for seawater desalination. A major operational problem of $\mathrm{RO}$ membrane filtration systems is biofouling - biomass growth causing an unacceptable membrane performance decline. Biofouling reduces the produced water quantity and quality and increases costs. The need for fouling remediation is mainly derived from destructive trial-and-error research with practical membrane modules. Therefore, a clear need existed for the development of a small-sized membrane fouling simulator (MFS) for systematic, low-cost studies. Since the introduction of the MFS in 2006, many articles have appeared which are evaluated in this review. The review describes (i) the location of biofouling in full-scale installations, (ii) development of MFS, (iii) characterization, reproducibility and representativeness of fouling development in the MFS, (iv) applications such as assessing the impact of anti-scalant or biocide dosage, phosphate limitation, feed spacer geometry and linear flow velocity and (v) early warning for biofouling. MFS studies have increased the understanding of biofouling and enabled improved practical membrane performance such as selection of dosed chemicals and feed spacer design. Future MFS studies are anticipated to enable the development of advanced biofouling control strategies.
\end{abstract}

Keywords: Seawater desalination; Reverse osmosis membrane; Biofouling; Membrane fouling simulator; Early warning

\section{Introduction}

Membrane-based water treatment processes, such as desalination, are applied increasingly to produce high quality water from a wide range of water types such as seawater and wastewater. The development of advanced pressure-driven reverse osmosis ( $\mathrm{RO})$ membrane installations enabled to improve high salt rejection and increase of permeate flux [1,2].
In membrane-based water treatment systems, membrane fouling is considered a major problem, causing an increase in pressure drop between the feed and brine lines which is referred to as feed channel pressure (FCP) drop or feed concentrate pressure [3], the decline of flux and salt rejection. Therefore, fouling development in membrane systems leads to an increase of up to $50 \%$ in operational costs and hampers the amount and quality of produced water [4].

* Corresponding author.

+ Shared first authorship.

1944-3994/1944-3986 @ 2018 The Author(s). Published by Desalination Publications.

This is an Open Access article. Non-commercial re-use, distribution, and reproduction in any medium, provided the original work is properly attributed, cited, and is not altered, transformed, or built upon in any way, is permitted. The moral rights of the named author(s) have been asserted. 
The consequences of fouling can be (i) increase of required feed pressure to maintain water production and consequently higher energy consumption, (ii) frequent chemical cleaning of the membranes, (iii) shortening lifetime of the membranes [5]. Therefore, in a membrane desalination installation, once the FCP increase or the flux reduction deviates more than $15 \%$ compared with the start-up values, corrective actions are taken to re-establish the original membrane performance [2]. Hence, development of biofouling monitoring strategies and early detection of biofilm formation in membrane systems is required $[6,7]$.

Different fouling types occur at the same time and may interact with each other [8]. Four types of fouling can be distinguished: scaling (inorganic), particulate, organic fouling, and biofouling. In general, scaling can be prevented by the dosage of anti-scalant or acid to the feed water. Colloidal or particulate fouling can be easily managed by pretreatment processes, for example, by ultrafiltration or cartridge filtration. Organic fouling can be prevented by pretreatment. Therefore, all types of fouling except biofouling can be managed. Membrane autopsy, a destructive membrane element study, is commonly applied to diagnose membrane fouling by visual inspection and analysis of accumulated deposits.

With the identification of biofouling as a key problem in membrane installations [2,9-13], biofouling studies have been intensified [14-20]. Many publications show that, until now, biofouling is seen as a significant practical problem in $\mathrm{RO}$ and nanofiltration (NF) membrane systems.

Biofouling is caused by the accumulation of microorganisms and extracellular polymeric substances (EPS) on a surface, which eventually build a biofilm, resulting in an unacceptable membrane performance decline [2]. Biofilms consist predominantly of bacterial communities enmeshed in a self-secreted polymeric matrix, which are usually referred to as EPS [21]. The microbial biofilm is developed by dynamic processes: (i) reversible attachment by attractive interactions between membrane surface and bacteria, (ii) irreversible attachment by specific or non-specific bacterial adhesions, (iii) micro-colony formation, (iv) biofilm maturation, and (v) dispersion [22]. It is claimed that even if $99.9 \%$ of all bacteria are eliminated by pretreatment, some bacteria will still enter the membrane system, adhering and multiplying utilizing biodegradable nutrients in the water passing the pretreatment $[23,24]$.

Until recently, fouling studies were mainly based on an experimental approach with pilot or industrial filtration installations containing industrial size (40-inch length by 4 , 8 , or 16 -inch diameter) membrane modules. The identification of fouling was based on the measurement of operational parameters such as FCP followed by destructive membrane autopsy studies. Therefore, developing devices simulating the biofouling via non-destructive, in-situ high-resolution imaging of the membrane and spacer is highly demanded $[25,26]$. Such device should be representative for conventionally used membrane modules, thus involving the used materials (properties and structure) such as membrane and spacer, the height of the flow channels and hydraulics. The membrane fouling simulator (MFS) was introduced in 2006 [4] and since then many articles have appeared on various research aspects of biofilm characterization [2,3,27-36], biofouling control [5,37-49], and strategies for early warning of biofouling [50-55] applying the developed MFS.

Early detection of biofilm growth enables directed corrective measures at an early stage preventing biofouling occurrence before reaching critical performance loss values. In present practice, corrective cleanings are applied at a later stage, based on a $15 \%$ deviation from the starting value for the pressure drop. An early detection of biofilm formation, followed by corrective measures, may allow a more effective control of the biofilm than curative cleaning measures applied at a later stage. Early detection of biofouling in an MFS can be achieved by sensitive pressure drop measurements and with non-destructive, real-time imaging techniques such as nuclear magnetic resonance (NMR) imaging, oxygen sensing using luminescent planar optodes, and optical coherence tomography (OCT). The developed MFS has proven to be a suitable tool to increase the understanding of RO fouling phenomena and to evaluate strategies to (i) delay the built up of biofilms, (ii) reduce the impact of accumulated biomass on membrane performance and (iii) remove the biomass from the membrane system. It is anticipated that future MFS research will lead to the development of more effective biofouling control strategies.

This review provides a critical overview on the development of the MFS and the applications aiming at prediction, prevention, and control of biofouling in practical $\mathrm{RO}$ and NF installations. MFS applications include (i) impact of feed water composition for evaluation and selection of pretreatment options, (ii) selecting of chemical type and optimizing of chemical dosage, (iii) testing of novel membranes or feed spacers, (iv) evaluation and optimization of alternative biofouling control strategies, and (v) early warning for biofouling.

\section{Localization of the biofilm formation}

\subsection{Increased pressure drop and biofilm accumulation in a pilot system}

Identifying the biofilm accumulation zone in membrane installations is required to enable development of a suitable MFS. A membrane installation has a large number of pressure vessels, each containing up to eight spiral-wound membrane modules in series. A membrane installation can have a tapered configuration. This means that the concentrate of a pressure vessel can be fed into a second pressure vessel, increasing the total water production of the installation. An industrial size membrane element has a length of $1 \mathrm{~m}$ (40 inches) and contains membrane sheets with a length of $0.93 \mathrm{~m}$ [31].

The increase in FCP and biomass concentration in a membrane installation was assessed over individual membrane elements of a full-scale installation (Fig. 1(a)) [55]. After long-term operation (146 d), a much stronger FCP increase (Fig. 1(b)) and higher accumulated biomass concentration (Fig. 1(c)) were observed in the parallel first membrane elements compared with the rest of the elements in the installation [55].

Studies at full-scale membrane installations with strongly reduced membrane performance showed the highest biofilm concentrations at the lead membrane inlet side (Fig. S1). This is in agreement with the findings of other studies $[2,23,24]$. 


\subsection{Identification of major biofouling zone}

To simulate the practical situation, Vrouwenvelder et al. [33] developed a prototype test cell with nearly the same membrane length $(0.90 \mathrm{~m})$ as membranes in spiral-wound modules $(0.93 \mathrm{~m})$. To enable placement of the sheets of membrane and spacer sampled from the membrane element in the prototype test cell, the prototype test cell length was made slightly shorter than a membrane module [33]. This prototype monitor had a width of $0.32 \mathrm{~m}$, a $7 \mathrm{~cm}$ thick Perspex cover lid, 10 bolts over the length to close the monitor, and one permeate collection channel.

Compared with a membrane module, this prototype monitor had an identical (i) feed spacer channel height and (ii) materials of spacers and membranes. To be representative of membrane elements, an appropriate monitor should have the same relationship between cross-flow velocity and FCP. Therefore, this relationship between cross-flow velocity and FCP was assessed for a membrane module in a single element pressure vessel and the prototype monitor.

The relationship was calculated using the friction coefficient term, for practical membrane elements, reported by Schock and Miquel [56] as follows (Eq. (1)):

(a)

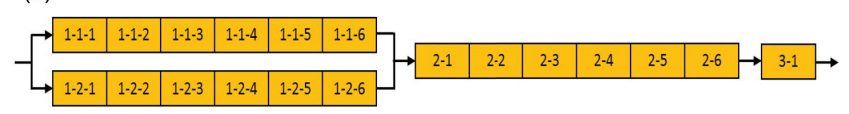

(b)

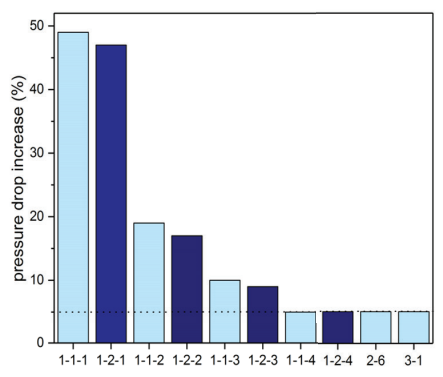

(c)

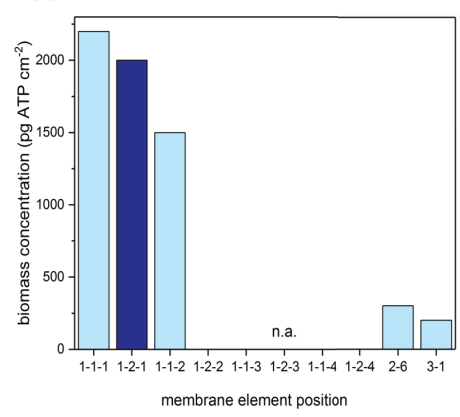

Fig. 1. Schematic positions of spiral-wound membrane modules in the pressure vessels and identification of biofouling distribution in nanofiltration (NF) membrane installation. (a) Position of two parallel pressure vessels (1 and 2) and membrane elements (1-6) in the NF installation. Membrane modules 1-1-1 and 1-2-1 indicate the lead membranes from the two parallel pressure vessels. (b) The feed channel pressure drop (FCP) increase and (c) accumulated biomass concentrations of membrane elements after $146 \mathrm{~d}$ of operation. The dotted line represents estimated limit of detection [55]. n.a.: not analyzed.

$$
\Delta P=\lambda \cdot \frac{\rho \cdot v^{2}}{2} \cdot \frac{L}{d_{h}}
$$

where $\lambda$ is the friction factor, $\rho$ is the specific density, $v$ is the cross-flow velocity, $L$ is the membrane length and $d_{h}$ is the hydraulic diameter.

The calculated data of the relationship between linear flow velocity and FCP precisely matched with the measured data for the membrane element, while there was a distinct difference between measured and calculated data for the prototype test cell. It can be concluded that this prototype monitor with a membrane length of $0.90 \mathrm{~m}$ and width of $0.32 \mathrm{~m}$ is not representative of practical membrane modules [33].

Addition of a biodegradable organic nutrient to the test cell feed water caused an FCP increase over the test cell. In particular, the FCP was strongly increased over the test cell first half $(0-0.45 \mathrm{~m})$, indicating that most of the biomass had accumulated at the feed side of the test cell. Studies without organic compound dosage, such as membrane module studies from practice showed that biofouling occurred in the first $0.20 \mathrm{~m}$ of the lead membrane element $[2,4]$.

The studies with (i) pilot plant, (ii) full-scale installations and (iii) the prototype monitor showed that it would be sufficient to develop a monitor with a membrane length of $0.20 \mathrm{~m}$ to study biofouling development and control strategies in spiral-wound membrane systems (Fig. 2).

\section{Development of the MFS}

\subsection{Design and hydraulics of MFS}

\subsubsection{Design of MFS}

Based on the localization of the biomass, a small monitor was developed. The MFS contains $0.20 \mathrm{~m} \times 0.04 \mathrm{~m}$ sized membrane and feed spacer sheets (Fig. 3) [4]. The first-generation MFS was constructed with two stainless-steel parts (bottom and top) sandwiching membrane, feed, and permeate spacer sheets. The MFS contained connectors for the separated flow of feed water, brine, and produced water. Also, connections were made for monitoring the applied pressure and FCP over the MFS length as well as the pressure drop over the membrane (trans-membrane pressure drop). A sight glass allowed macro and microscopic in-situ studies of the spacer
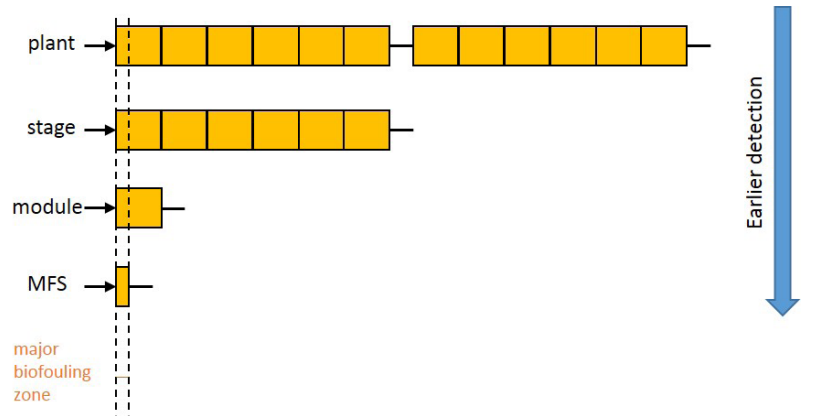

Fig. 2. Early detection of biofouling at a membrane fouling simulator (MFS) supplied with water source of the membrane filtration installation. The major biofouling zone where the biofouling starts is covered by the MFS [54]. 
and membrane in the MFS. A transparent window enabled to use a microscope for accurate $(\mu \mathrm{m})$ fouling thickness measurements. To avoid the growth of phototrophic micro- and macro-organisms, the glass was covered to prevent light intrusion. A set-up for stable and automatically controlled feed water flow conditions in MFS systems [57] and criteria for MFS design have been developed $[4,33,58]$.

\subsubsection{Influence of permeate production}

Similar FCP increase and biofilm formation were found at the inlet side of membrane modules at parallel positions in an NF system operated with or without production of permeate. Mass transfer calculations demonstrated that, compared with the diffusive flux, the permeate flux plays a minor role in the transport of nutrients to the biofilm [36]. Studies at

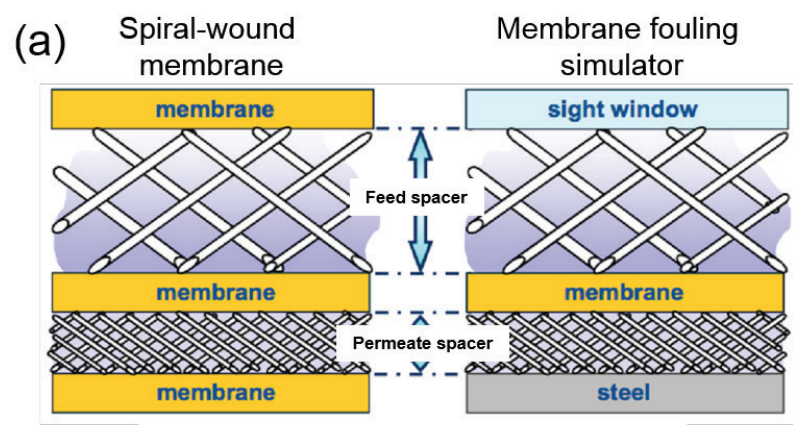

(b)

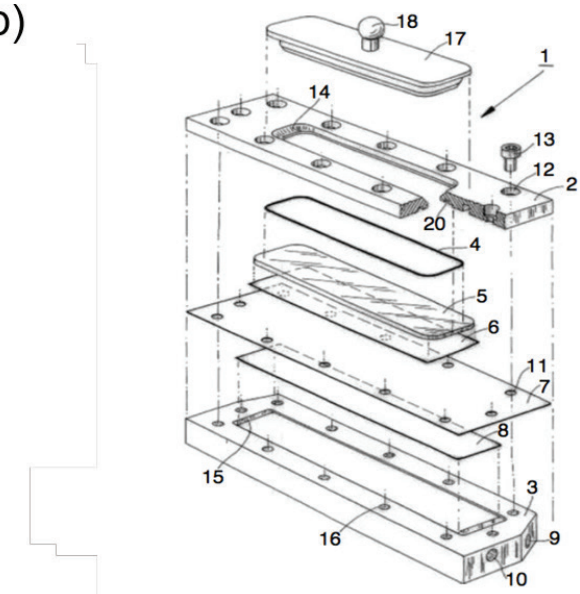

(c)

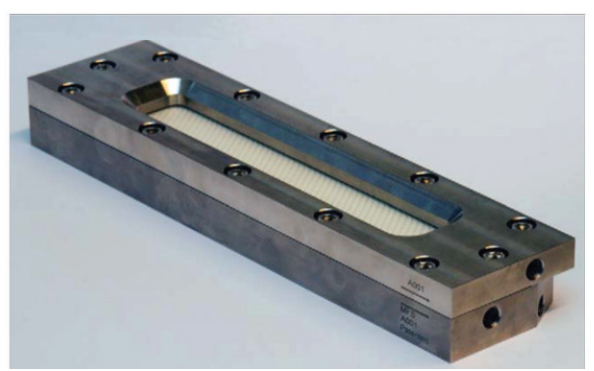

Fig. 3. Design of MFS to simulate fouling in spiral-wound membrane modules. (a) Identical location and height of spacers and membranes in spiral-wound membrane modules in practice and MFS. (b) A patented schematic diagram (patent NL 1028474) [59] and (c) developed MFS device [4,33]. test-rig and full-scale installations with varying water sources showed that the accumulated biomass amount matched accurately with the FCP increase irrespective of whether permeate was produced or not [2]. This means that FCP increase is the important operational parameter to determine the stage for cleaning of a biofouled full-scale membrane system [47]. In spiral-wound RO membrane filtration installations, development of biofouling is mainly provoked by the feed spacer [46]. In other words, the biofilm is formed regardless of whether permeate is produced or not, and the amount of accumulated biofilm has most impact on the FCP [28].

A second generation of MFS units were manufactured from poly(methyl methacrylate) (PMMA) and poly(vinyl chloride) (PVC) material. These MFSs showed the same firmness, hydraulic behavior, reproducibility and performance of the first-generation steel MFS units. Advantages of the PMMA and PVC MFS units are the lower production costs and a higher flexibility in producing tailor-made flow cells, enabling accommodation of feed spacers of different thickness [37]. More recently, MFS units have been developed with permeate production with various dimensions for the membrane and spacer sheets.

\subsubsection{Hydraulic characterization of MFS with the spiral-wound membrane module}

The relation of linear flow velocity and FCP over the MFS was measured and compared with the relationship for a spiral-wound membrane module in a single element pressure vessel [4]. The relation was also calculated by applying Eq. (1) [56].

Both the measured and calculated data for the MFS suited properly with the data for membrane modules, indicating that the MFS has identical hydraulic behavior as spiral-wound membrane elements (Fig. 4).

\subsection{Representativeness of MFS}

To evaluate the MFS representativeness for membrane module fouling development found in practice, comparative (a)

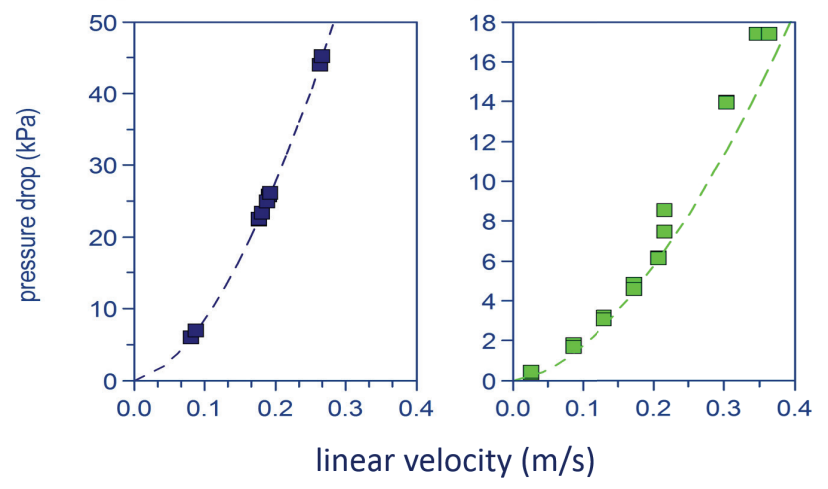

Fig. 4. Relation between linear flow velocity $(\mathrm{m} / \mathrm{s})$ and FCP $(\mathrm{kPa})$ in (a) a spiral-wound membrane element $(1.00 \mathrm{~m})$ and (b) the MFS $(0.20 \mathrm{~m})$ with the different lengths. The measured data (represented by blue and green color markers; $\mathbf{\square}, \mathbf{\square}$ ) and calculated data (dotted line) matched [4]. 
studies have been conducted [4]. An MFS and a membrane element in the test-rig were operated simultaneously in parallel to a full-scale membrane filtration plant. The test-rig and full-scale plant both contained spiral-wound membrane modules. At the end of the study, a destructive method was used to quantify the accumulated amount of biofilm on the membrane and spacer sheets in the MFS, test-rig membrane element, and the full-scale system lead membrane module. The accumulated amount of biomass decreased over the MFS and membrane element length (Fig. 5(b)). A comparable increase of FCP was found over the MFS and the test-rig membrane element for $17 \mathrm{~d}$ (Fig. 5(a)). After $17 \mathrm{~d}$, a significant difference of the FCP increase was observed between the MFS and the membrane element in the single element test-rig (Fig. 5(a)). The behavior can be explained by the low amounts of biomass after the first $0.20 \mathrm{~m}$ of the element (Fig. 5(b)), causing a low FCP over the $0.93 \mathrm{~m}$ long membrane elements of the test-rig compared with the $0.20 \mathrm{~m}$ long MFS. It can be concluded that the biomass on the first $0.20 \mathrm{~m}$ caused most of the membrane module FCP increase.

A comparison study involving (i) MFS units containing $\mathrm{RO}$ or NF membrane sheets, (ii) RO or NF membrane elements in test-rigs, and (iii) an RO membrane in a full-scale installation was performed. During the $41 \mathrm{~d}$ research period, the same development of FCP occurred over the two parallel MFS units. The same biomass amount was accumulated in all systems of single element test-rig and full-scale installation with MFS (Fig. 6).

An MFS study was carried out to assess whether short-term biofouling experiments with biodegradable nutrient dosage are predictive for long-term biofouling development with no addition of nutrient [60]. Feed spacer plays an important role in biofouling. Therefore, this study addressed six feed spacers differing in geometry [60]. MFSs were operated with the same membrane and same water and feed flow, but with different geometry spacers [60]. During the shortterm study, biofilm development was accelerated by dosing biodegradable nutrient to the MFS. The long-term study was done without nutrient dosage. For the short ( $9 \mathrm{~d}$ ) and longterm (96 d) biofouling experiments, a comparison was made in order to better understand the role of feed spacer geometry on the amount of biomass accumulation. It was concluded that the feed spacers presented an equivalent biofouling performance for the short-term experiments with addition of nutrient and the long-term experiment without dosing nutrient. The six different geometry feed spacers showed about the same accumulated biomass amount; however, the biofouling impact on FCP increase clearly differed. The six feed spacers showed the same ranking for the biofouling impact on

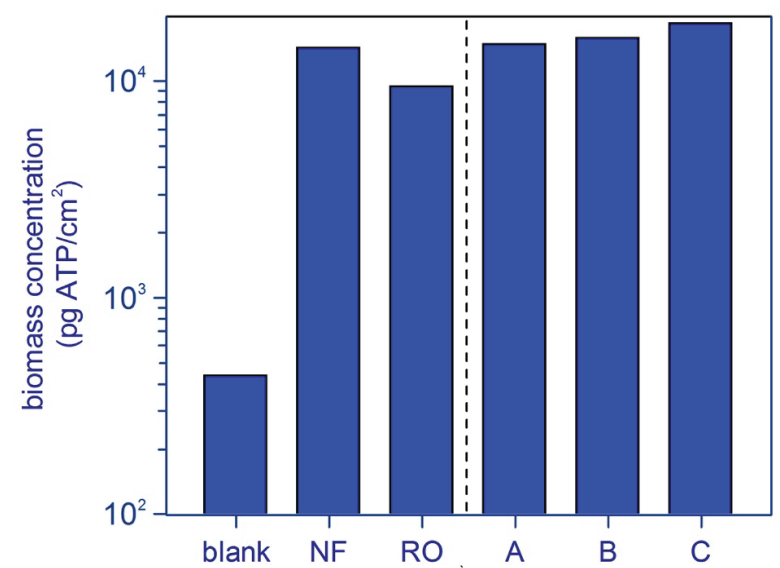

Fig. 6. Comparison of accumulated biomass in MFS, test-rig and RO installation. The biomass concentrations (i) in the MFS with NF or RO membranes, (ii) in a test-rig with (A) NF, (B) RO spiral-wound membranes, (iii) (C) in an RO membrane element from the full-scale installation. All systems were operated in parallel at a water production facility for $41 \mathrm{~d}$, except the blank. The blank was operated for $41 \mathrm{~d}$ with tap water using MFS with NF membrane [1]. (a)

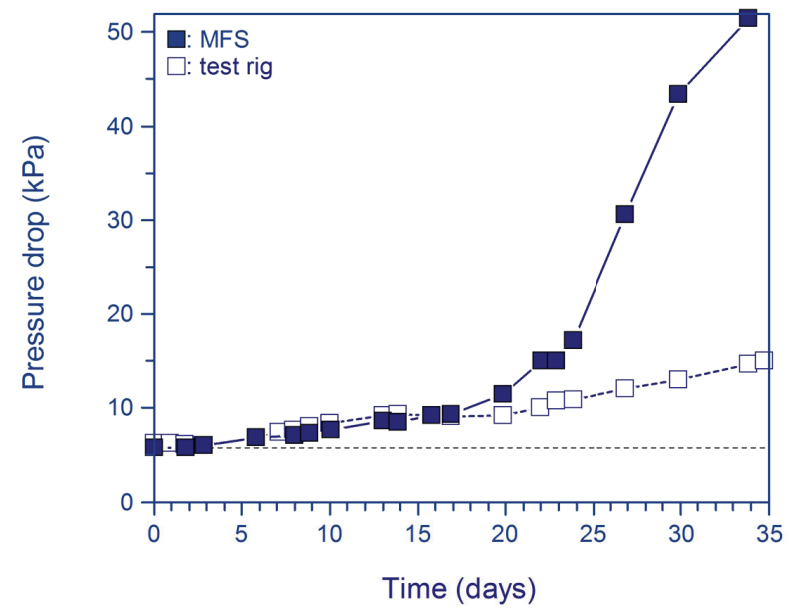

(b)

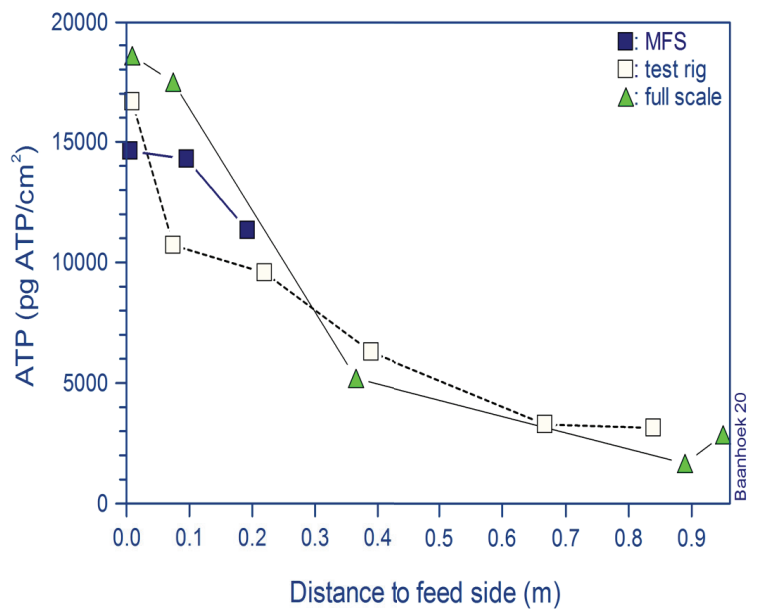

Fig. 5. Comparison of FCP increase and biomass concentration between MFS and membrane installations. (a) Comparison of FCP increase in time over the membrane element and MFS. (b) Biomass concentration (pg ATP/ $\mathrm{cm}^{2}$ ) over the length of the MFS, membrane modules from test-rig and full-scale installation [4]. 
FCP increase for the short- and long-term biofouling analysis. Using MFSs, short-term biofilm studies with nutrient dosage proved to be representative and suitable for predicting biofouling after long-term operation [60].

In summary, the MFS has shown to be representative for the increase in FCP analysis and biomass accumulation in spiral-wound membranes used in practice [1]. Short-term biofilm studies with biodegradable nutrient dosage are suitable to study biofouling processes.

\subsection{Reproducibility of MFS}

Reproducibility of FCP development and biomass accumulation has been investigated with MFS units operated in parallel with the same feed spacers and membranes for (i) long-term analysis without nutrient addition and
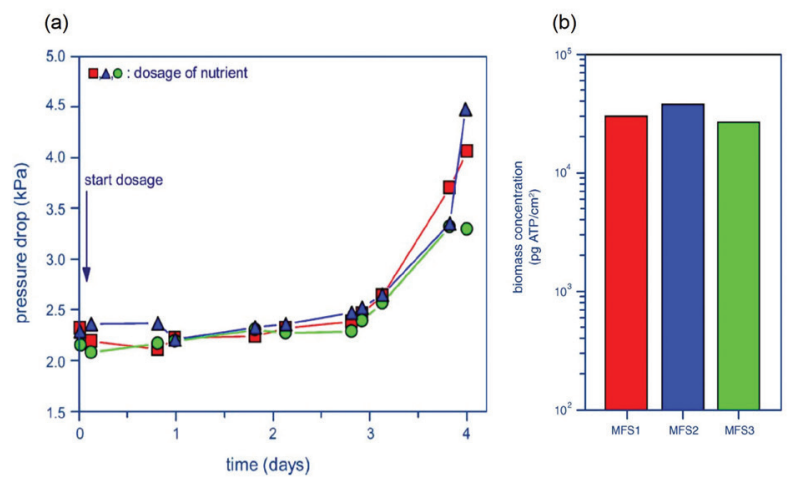

Fig. 7. Reproducibility of MFS regarding FCP and biomass accumulation over three parallel MFSs ( ${ }^{-}$MFS1, $\Delta$ MFS2, • MFS3) fed with water supplemented with $200 \mu \mathrm{g}$ acetate C/L. The identical (a) FCP increase in time and (b) biomass concentrations on the membrane and spacer in the MFSs were determined after $4 \mathrm{~d}$ operation [4]. (ii) short-term analysis with the nutrient addition to the MFS feed water to accelerate the biofouling growth rate.

The study was done at a site of a full-scale membrane installation and the feed water of the $\mathrm{RO}$ installation was fed to parallel MFS units without and with supplementation of nutrients. A35 d parallel operated MFS study showed identical (i) FCP increase and (ii) accumulated amount of biofilm [1].

Short-term studies (4 and $10 \mathrm{~d}$ ) with nutrient dosage presented the same development of FCP and biomass accumulation in MFS units operated in parallel [4,38,61].

In summary, the same development of biofouling indicators was found for parallel MFS studies, indicating that the MFS units provide reproducible data (Fig. 7) [4].

\section{Applications of MFS to evaluate biofilm growth and cleaning strategies}

\subsection{Acceleration by biodegradable organic carbon dosage}

In conventional water treatment processes, biological filtration with sand and granular activated carbon restricts the concentration of biodegradable organic carbon of the water, reducing the microbial growth potential. The effect of the nutrient concentration on biofouling was studied by operating four MFSs in parallel, at constant linear flow velocity, fed with water supplemented with increasing biodegradable organic compound concentrations $(0,100,200$ and $400 \mu \mathrm{g}$ acetate C/L) [23].

During the $14 \mathrm{~d}$ of study, the control MFS without nutrient dosage showed no change in FCP. An increase in FCP was observed with the addition of a nutrient (Fig. 8(a)). With increasing amount of nutrient in the feed water, a faster and stronger FCP increase was found (Fig. 8(a)). At the end of the study, the MFS membrane and spacer coupons were analyzed for biomass accumulation. The biomass accumulation (adenosine triphosphate; ATP) in the MFS showed an increase correlated with the concentration of organic nutrient (a)

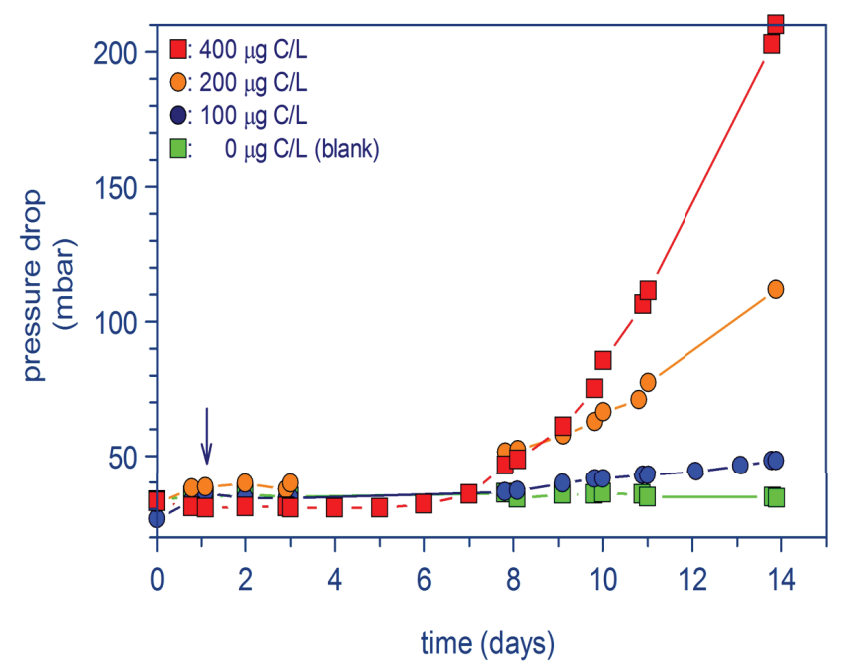

(b)

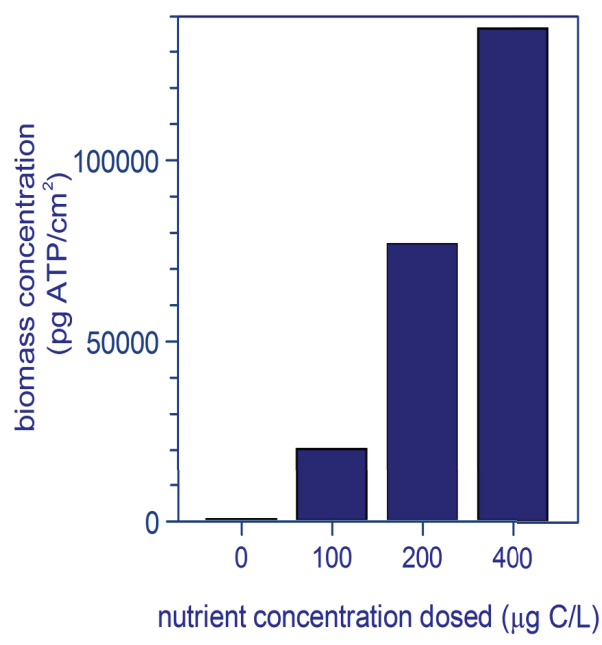

Fig. 8. Accelerated biofilm formation with increasing nutrient dosage. (a) FCP increase over time with and without (blank) dosage of different concentrations of acetate $(0,100,200,400 \mu \mathrm{g}$ acetate C/L) to the feed water. The arrow indicates the starting point of the nutrient dosage. (b) Amount of accumulated biomass on the membrane and spacer in the MFS after $14 \mathrm{~d}$ of operation [28]. 
in the MFS feed water (Fig. 8(b)). The increase of the acetate concentration resulted in a denser and more visible biomass formation on the surface of the membrane and feed spacer (Figs. S2 and S3). Reducing the feed water nutrient amount diminished the FCP increase and accumulated biomass amount (Fig. 8(b)) [28,62]. The reduction of water nutrient concentration by pretreatment may be pursued to reduce membrane biofouling [63].

\subsection{Biofouling inhibition by phosphate limitation}

The microbial growth of biofilms is affected by the availability of nutrients such as organic carbon and phosphorus. In general, organic carbon is the microbial growth-limiting compound (section 4.1). Studies with phosphorus or phosphate limitation of microbial growth were observed for wastewater, rivers, surface and seawater, and drinking water [64-75]. Recently, biofouling control by phosphate limitation has been demonstrated for membrane systems [42-44]. The common molar ratio for carbon (C), nitrogen $(\mathrm{N})$ and phosphorus $(\mathrm{P})$ in microbial biomass is 100:20:1.7 [76]. Compared with carbon, low phosphorus levels are needed to obtain microbial growth. Among the soluble forms of phosphorus such as orthophosphate, polyphosphates and dissolved organic phosphorus in natural waters, the most available for the use of biological systems is orthophosphate [77]. Orthophosphate is mentioned as phosphate in this review unless otherwise stated.

A study was carried out with several MFSs in parallel with water from municipal water treatment plant named "Jan Lagrand" in Heemskerk (Netherlands) showing that the biofilm growth can be restricted by phosphate limitation, despite the presence of high amounts of organic nutrients in the feed water (Fig. S4) [45]. The combined dosage of organic (acetate) and inorganic (phosphate) nutrients to the water feeding the MFS resulted in a fast increase of FCP through the MFS [45]. In the MFSs fed with only acetate, only phosphate or no dosage, only a small FCP increase was obtained (Figs. 9(a) and (b)). The low phosphate concentration restricted biofilm growth (Figs. 9(c) and (d)). (a)

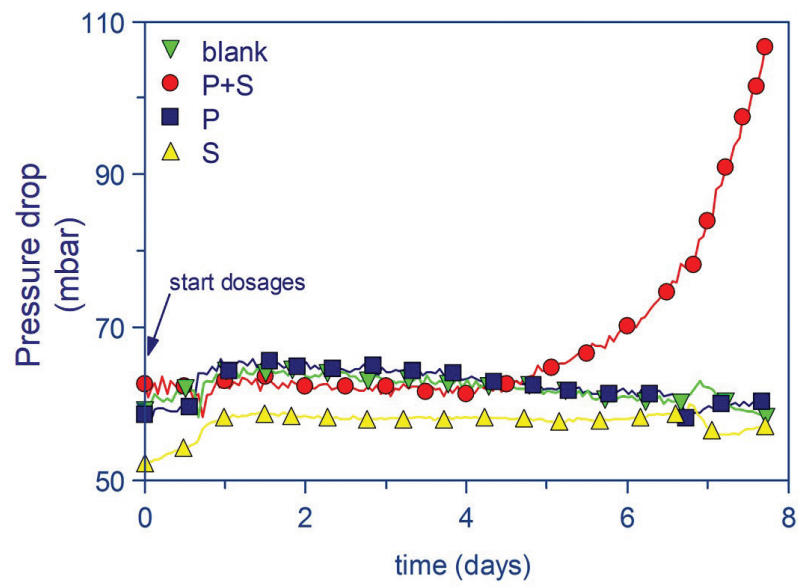

(c)

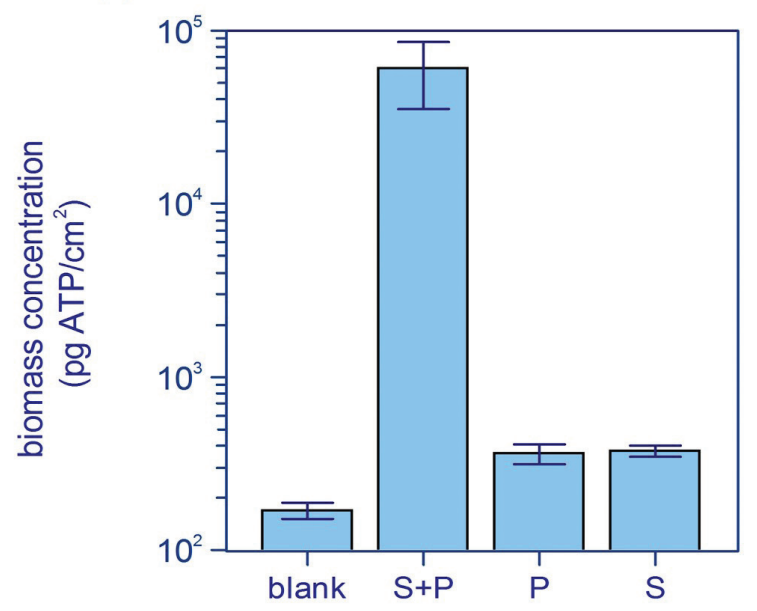

(b)

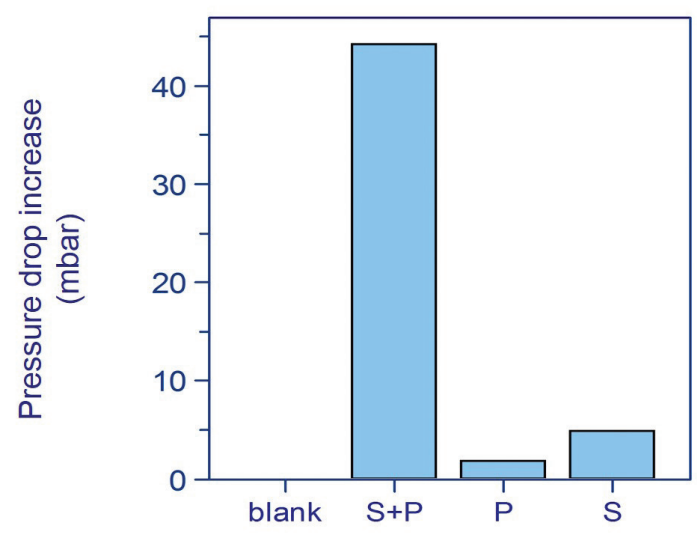

(d)

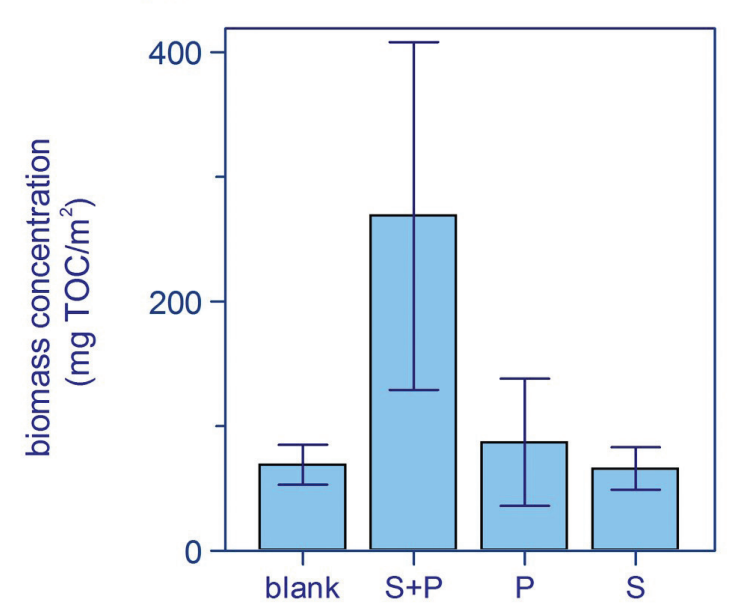

Fig. 9. Impact of phosphate in feed water on biofilm formation. (a) FCP increase in time, (b) FCP increase, biomass accumulations regarding (c) ATP and (d) TOC within $8 \mathrm{~d}$ of MFS operation supplied with feed water containing phosphate and substrate (S+P), phosphate (P), substrate (S) and without dosages (blank) [45]. Biofilm formation is limited at very low phosphate concentrations. 
MFS studies demonstrated that the FCP increase and biomass accumulation is restricted by a very low concentration of phosphate in the water source, even when the water has high organic carbon concentrations [45].

\subsection{Impact of anti-scalant dosage}

Dosing anti-scalant to the feed water of an RO installation is necessary to avoid scaling. Scaling is defined as the precipitation of mineral salts in the $\mathrm{RO}$ membrane modules. However, use of anti-scalant may simultaneously cause enhanced biofilm accumulation and therefore biofouling, depending on the dosing amount and the type of anti-scalant used [78].

Two phosphonate-based and two phosphorus-free anti-scalants were tested in an MFS study using phosphate-limited water (section 4.2) from water treatment plant "Jan Lagrand" in Heemskerk. The influence of the anti-scalants on biofilm formation was analyzed with
MFSs fed with the anti-scalant and organic nutrient [45]. The dosage of the two phosphate-free anti-scalants with an organic nutrient resulted in a low FCP increase and low biofilm formation. The phosphonate-based anti-scalants caused a strong FCP increase and a high biofilm formation on the surface of the membrane (Fig. 10). It is assumed that the phosphate in the phosphonate-based anti-scalant can be a major factor to induce biofilm formation [45]. The phosphate-based anti-scalants seem to contain biodegradable nutrients, since the growth of these anti-scalants (AS1+S and AS2+S) is stronger than the control $(P+S)$ (Fig. 10).

The MFS units can be used to rapidly evaluate and select anti-scalants, which do not contribute to biofilm development $[41,79]$.

\subsection{Impact of biocide dosage}

A strategy to control biofouling of membrane system is proposed. This consists in dosing biocides to the feed water. (a)
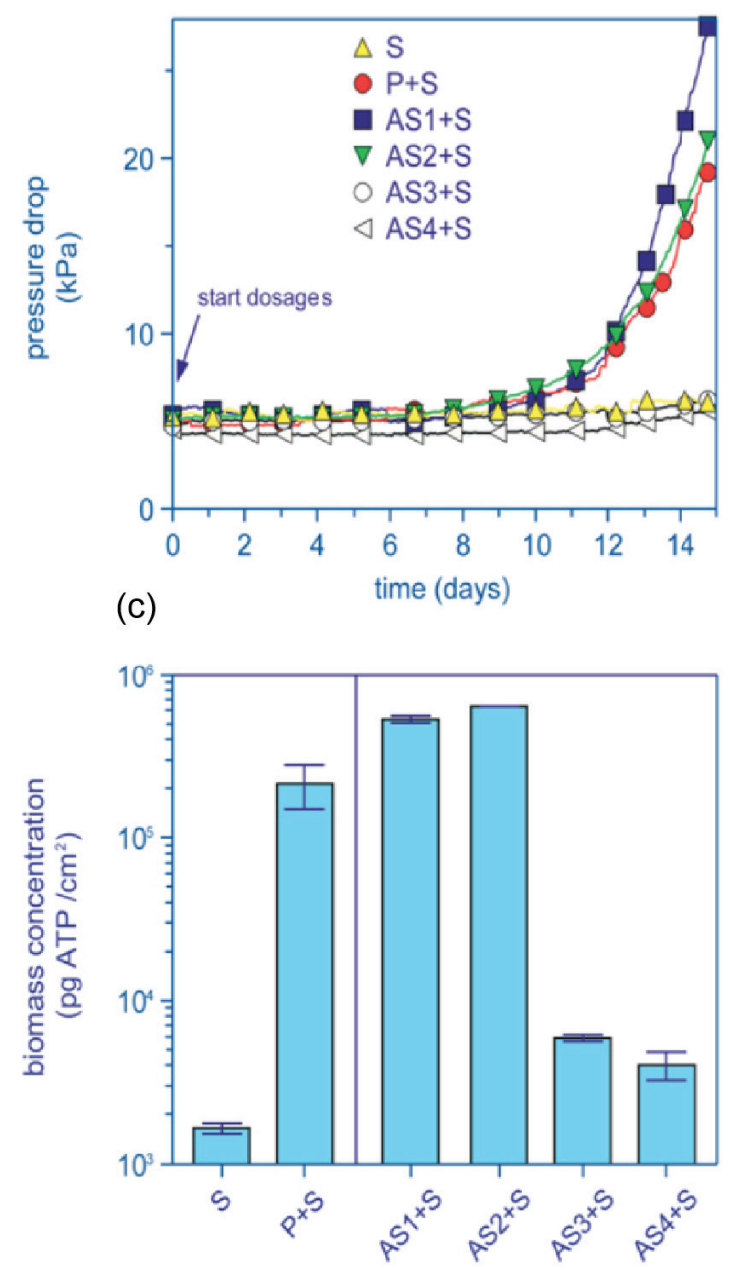

(b)
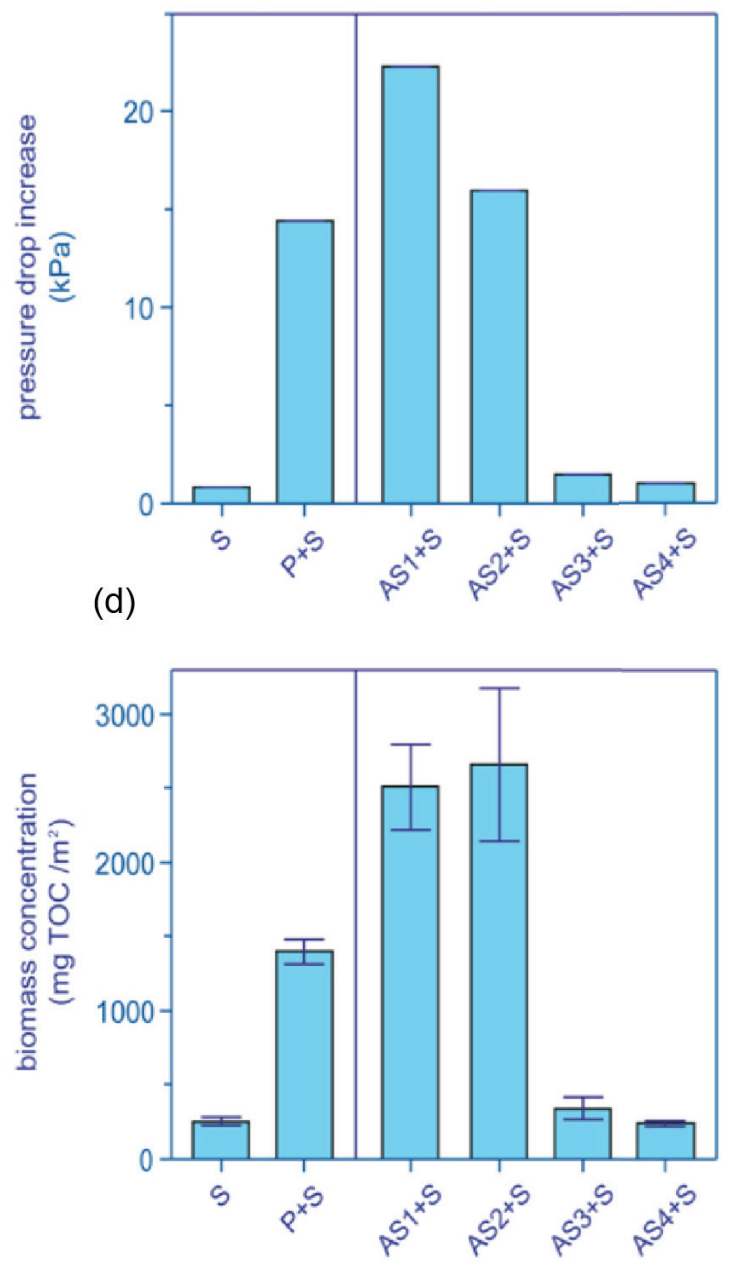

Fig. 10. Impact of phosphonate-based (AS1, AS2) and phosphate-free anti-scalants (AS3, AS4) dosage on biofilm formation. (a) FCP increase with time, (b) FCP increase, and biofilm amount regarding (c) ATP and (d) TOC within 15 d MFS operation supplied with water containing substrate $(S)$, phosphate and substrate $(P+S)$, and four anti-scalants with substrate $(A S 1+S, A S 2+S, A S 3+S$, AS4 + S) [45]. 
The rationale of applying biocides is to inactivate biomass and thereby preventing biofilm accumulation [5,47].

An MFS study to evaluate a biofouling inhibitor (BI) showed within $17 \mathrm{~d}$ that the biofouling inhibitor caused a slightly higher increase in FCP and higher biomass accumulation compared with the blank without dosages of BI and substrate (Fig. 11) [3]. It means that dosage of this biocide contributes to biomass accumulation due to the presence of biodegradable compounds in the biocide (Fig. 11: comparison of BI and blank), causing bacterial growth. So, dosing of a biocide from the start-up of an installation may lead to enhanced biofilm formation. A hypothesis for the growth found for the biocide could be the presence of a conserving chemical or contamination or the biocide may be biodegradable itself.

The impact of 2,2-dibromo-3-nitrilopropionamide (DBNPA) dosage on biofouling control was assessed [5]. The continuous dosage of DBNPA $(1 \mathrm{mg} / \mathrm{L})$ prevented FCP increase and biomass accumulation in the MFSs during a running time of $7 \mathrm{~d}$, showing that biofouling can be managed by preventive DBNPA dosage (Fig. S5) [5]. In biofouled systems, continuous dosage of DBNPA (1 and $20 \mathrm{mg} / \mathrm{L}$ ) inactivated the accumulated biomass but did not remove the accumulated inactive cells and EPS and did not restore the original FCP (Fig. S6), indicating DBNPA dosage is not suitable for curative biofouling control [5].

The MFS unit can be used for biocide selection and optimization of dosing regime, such as dosing concentration and frequency, to prevent biofilm formation.

\subsection{Impact of flow regime on biofouling}

\subsubsection{Effect of linear flow velocity gradient in a membrane filtration installation}

In practical $\mathrm{RO}$ membrane installations, up to eight membrane modules are encased in series in a pressure vessel. At a pilot plant scale containing new non-fouled membranes, the highest FCP was observed in the lead membrane module and the FCP declined over the length of the membrane installation [55]. This decline of FCP with increasing distance from the feed side was attributed to the reduction of the water flow due to permeate production in the membrane elements, about $10 \%-12 \%$ for each element [55]. Therefore, the lead membrane module with the highest flow velocity caused most of the FCP increase over the total membrane installation.

Generally, the greatest amount of biofilm is observed in the lead membrane element of the pressure vessel $[2,80,81]$. Biofouling occurs at the location where the effect of accumulated biomass on performance is strongest [55].

\subsubsection{Effect of linear velocity}

Parallel MFS studies done at varying cross-flow velocities at the same nutrient dosage showed the same accumulated biofilm amount. The cross-flow velocity determined the FCP increase [35]. Reducing the cross-flow velocity may be an alternative method to restrict the FCP increase caused by the accumulated biomass [35].

\subsubsection{Effect of linear velocity variations}

A reversal of flow direction in pressure vessels can be an approach to decrease the biofilm impact on membrane performance such as FCP increase [35]. To assess the effect of linear velocity variations in a pressure vessel on biofouling, studies with four MFSs were performed. The MFSs were operated under two different linear velocities representing the lead membrane module $(0.163 \mathrm{~m} / \mathrm{s})$ and the last membrane module of the pressure vessel $(0.065 \mathrm{~m} / \mathrm{s})$. Two MFSs operated at $0.163 \mathrm{~m} / \mathrm{s}$ were supplemented with biodegradable nutrient $(100 \mu \mathrm{g}$ acetate C/L) and two other MFSs were operated at $0.065 \mathrm{~m} / \mathrm{s}$ without dosage of (a)

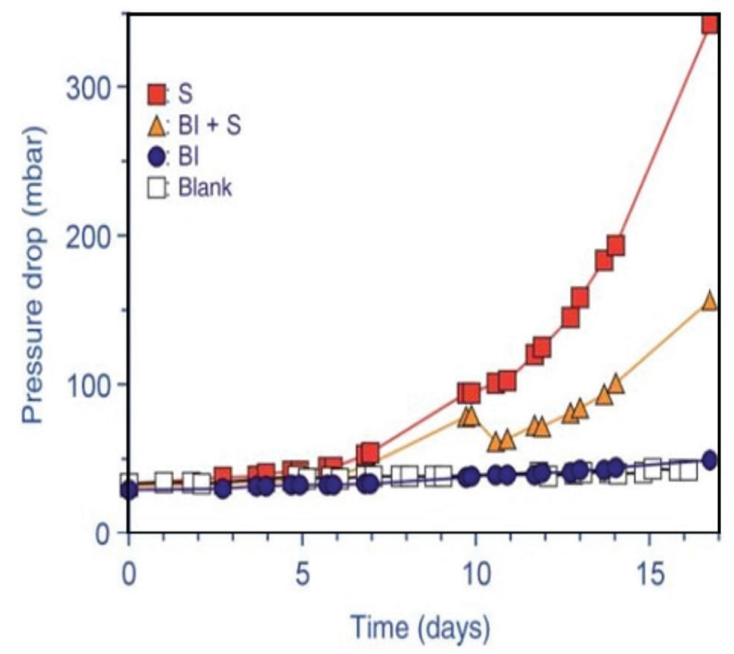

(b)

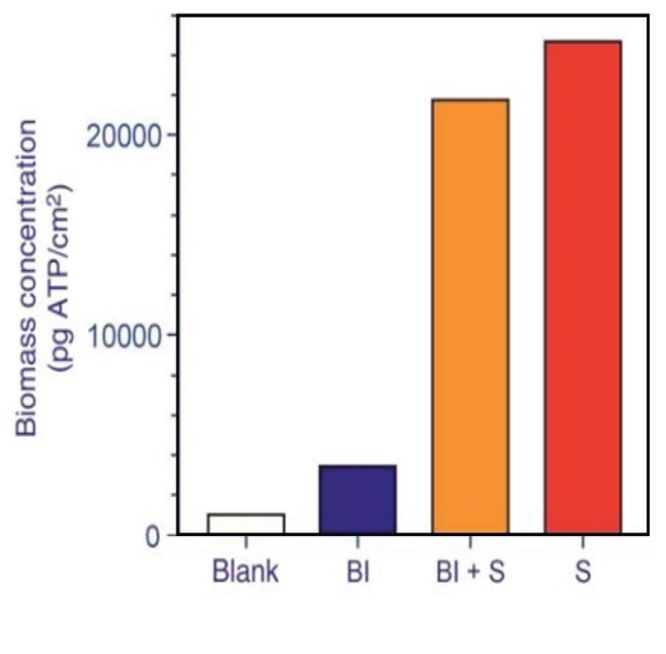

Fig. 11. Impact of biofilm inhibitor (BI) dosage on biofilm formation. (a) FCP increase in time and (b) the biomass concentrations after $17 \mathrm{~d}$ operation. The MFSs were operated in parallel, fed with water supplemented with substrate (S), biofilm inhibitor with substrate $(\mathrm{BI}+\mathrm{S}), \mathrm{BI}$ and without any dosage (blank) [3]. 
a nutrient [35]. After $6 \mathrm{~d}$, the MFSs with high linear flow velocity $(0.163 \mathrm{~m} / \mathrm{s})$ containing the nutrient $(100 \mu \mathrm{g} \mathrm{C} / \mathrm{L})$ showed a large FCP increase (Fig. S7(a)), resulted from the accumulated biomass. A subsequent reduction in linear flow velocity ( 0.163 to $0.065 \mathrm{~m} / \mathrm{s}$ to simulate flow reversal in the pressure vessel) resulted in a $73 \%$ reduction of the FCP compared with the starting FCP at $0.163 \mathrm{~m} / \mathrm{s}$ and only slightly higher than the starting FCP for the MFSs at $0.065 \mathrm{~m} / \mathrm{s}$ (Fig. S7(b)). The MFSs operated at $0.065 \mathrm{~m} / \mathrm{s}$ without nutrient dosage during $6 \mathrm{~d}$ caused no detectable FCP increase with time (Fig. S7(a)). A subsequent increase in linear flow velocity from 0.065 to $0.163 \mathrm{~m} / \mathrm{s}$ resulted in a jump of the FCP almost to the starting FCP determined for $0.163 \mathrm{~m} / \mathrm{s}$, while the biomass amount was maintained (Fig. S7(c)). Reduction of the linear flow velocity clearly caused an immediate and strong reduction of the FCP which is caused by accumulated biofilm, without influencing the accumulated biofilm amount [35].

Flow reversal in pressure vessels restrict the FCP increase caused by accumulated biomass. Feed flow reversal in pressure vessels may be efficient for biofouling management [35], and for other fouling types as well such as particulate fouling in the lead module and scaling in the last module [82].

\subsubsection{Effect of bubble flow}

Biomass accumulation and FCP development have been studied in MFS at varying flow regimes [34]. At cross-flow velocities as used in practical membrane installations, voluminous slime and filamentous biofouling structures (streamers) were developed in the flow channel causing an increase in FCP. Increased shear force by single phase flow of water resulted in the development of more streamers and a stronger FCP increase [34]. Bubble flow, water with air sparging, caused (i) the development of a more compact biomass and less streamers, and (ii) a much lower FCP increase compared with water flow only (Fig. S8) [34]. The biofilm developed under low shear conditions was easier to detach during periodic water flushing compared with a biofilm developed under high shear conditions (Fig. S9) [34]. Hydraulic cleaning has been shown as a potentially suitable cleaning strategy for biofouling control [18,83-85].

\subsection{Impact of feed spacer geometry}

The feed spacer is a crucial part of RO and NF membrane modules to keep the membrane sheets apart and to enhance water mixing [46]. Feed spacers have been shown to have a strong impact on biofouling [46].

MFS studies have been performed to evaluate feed spacers (i) as applied in practice, including varying spacer thickness [37], (ii) after modifications by hydrophilic, amphiphilic bactericidal and biocidal coatings [38,39,42], and with innovative geometries [29,44,48,86,87]. A novel strategy for a cost-effective development and evaluation of feed spacers was developed for biofouling and scaling control involving (i) numerical modeling, (ii) three-dimensional (3D) printing of spacers, and (iii) MFS testing of hydrodynamics and biofouling impact [43]. Siddiqui et al. [43] designed 3D printed feed spacers with different geometries giving a low FCP and low biofouling impact on membrane performance. In another study, the geometrical alteration of the feed spacers involving spacer strand and thickness, internal strand angle and the distance between strands. The modified geometry spacers showed a lower FCP at the same flow rate and a lower potential of biofilm formation (Fig. S10) compared with commercially available feed spacers [44].

Modified spacer geometries and surfaces may be a suitable solution to control biofouling [24]. The impact of spacer design on (i) biofilm development, (ii) membrane performance, and (iii) biofouling reduction can be studied using MFSs.

\subsection{Efficiency of preventive vs. curative biofouling cleaning}

Biofilms were pre-grown in MFS units and thereafter cleaned using sodium dodecyl sulfate and sodium hydroxide $(\mathrm{NaOH})$ and the cleaning efficiency was evaluated using NMR microscopy [40,88]. The NMR structural and water velocity images showed considerable changes in the biofilm amount and spatial localization after the cleaning. A small volume of accumulated biofilm had a strong impact on the effective membrane surface area [40]. Cleanings at an early biofilm formation stage were more efficient to remove biomass than cleanings performed at a later developed biofilm stage (Fig. S11) [40], illustrating the need for an early warning system.

\section{Early detection of biofouling}

\subsection{Need for early warning}

In spiral-wound RO systems, different types of fouling may occur simultaneously. To assess the role of an individual foulant on membrane performance would require monitoring the development of both individual and combined types of fouling. The main fouling type in extensively pre-treated water is biofouling [45].

As already mentioned in the introduction, the FCP increase and flux decline of membrane installations are considered as an operational problem when deviating up to $15 \%$ from the initial membrane performance values [2].

Cleaning based on the $15 \%$ criterion is most likely too late to control biofouling in all cases, so cleaning at an earlier stage should be pursued. To apply an anti-biofouling strategy at a suitable time, the development of an early warning monitoring system is required.

\subsection{Evaluation of MFS as an early warning system}

\subsubsection{Effect of permeate production}

The same increase of FCP and biomass accumulation was found in membrane elements from an identical location in an NF system, regardless of permeate production. The high biofilm amount accumulated in the lead elements of the membrane system was not affecting the permeate production and vice versa but resulted in a strong FCP increase over the membrane modules [29,36,46,54,86,87].

Therefore, an early warning system for monitoring of biofilm formation does not require permeate production [29,36,46,54,86,87]. 


\subsubsection{Membrane length in MFS}

A high amount of biomass was found in the lead RO elements from studies at the pilot and full-scale membrane installations $[2,33]$. A biofouling study with a test cell containing $0.90 \mathrm{~m}$ long sheets of the membrane and feed spacer showed a much stronger FCP increase and more biofilm formation at the inlet side of the test cell than at the outlet side, illustrating that biofilm predominantly was present at the lead membrane feed side [54]. Accumulated amounts of biofilm at the feed side of RO systems explained most of the FCP increase over the total RO system. Therefore, early warning detection of biofilm formation should be based on measurements at the RO installation feed side.

A system with $0.20 \mathrm{~m}$ membrane length, fed with the feed water of the RO installation, is adequate for an early warning application.

\subsubsection{Sensitive pressure drop monitoring in MFS}

In an NF pilot installation, the development of FCP was investigated over (i) individual membrane elements, (ii) individual stages and (iii) the total NF installation (section 3.2). To investigate the relationship between FCP increase and accumulated fouling, membrane autopsies on elements differing in FCP increase were performed. Biofilm started to develop at the water inlet side of the first membrane element of the lead pressure vessel. Early stage biofouling is accurately detected by monitoring the FCP over a separated first membrane element of an $\mathrm{RO}$ installation using an accurate pressure drop transmitter.

Monitoring the FCP with a sensitive pressure drop transmitter over a $0.20 \mathrm{~m}$ long early warning system provides early detection of biofouling, enabling early application of control measures.

\subsubsection{Sensitive and rapid biofouling detection in MFS}

Improved sensitive biofouling detection is achieved by an elevated cross-flow velocity of the early warning system (Fig. 12) [49]. The linear flow velocity determines the FCP of a clean system and the FCP increase originating from the accumulated biofilm. The FCP increase was correlated exponentially with the increase of linear flow velocity. Therefore, earlier detection of biofouling is enabled at elevated cross-flow velocity, enhancing the FCP measurement accuracy [49].

A higher cross-flow rate leads to a higher biodegradable nutrient load increasing the rate of biofilm accumulation [28,85,89-95]. Constant MFS operation at high cross-flow will increase (i) the accuracy of the FCP measurement and (ii) the rate of biofilm formation, enabling earlier warning of biofouling.

\subsection{Analytical methods for early detection of biofouling}

An FCP increase is not exclusively linked to biofouling. Early warning using an MFS monitored by sensitive pressure drop measurements can be combined with an autopsy of the spacer and membrane sheets sampled from the MFS to quantify accumulated ATP and total organic carbon (TOC) [54], or with non-destructive imaging methods such as optodes or

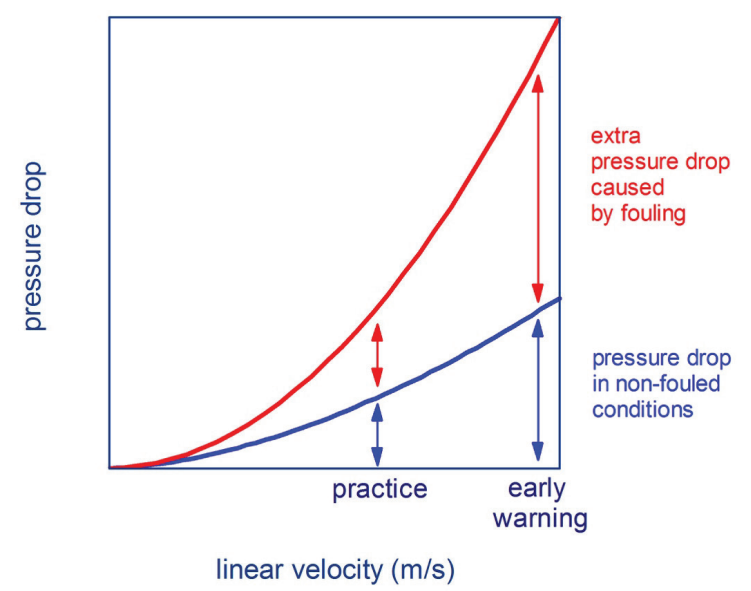

Fig. 12. FCP increase as a function of the linear flow velocity, illustrating that the effect of biomass concentration on FCP increase is affected by linear flow velocity. The difference between the FCP in non-fouling conditions and in fouling conditions is the FCP increase caused by accumulated biomass [49].

NMR microscopy. A method that recently gained interest for non-destructive imaging of biofilms is OCT $[51,96,97]$.

\subsubsection{Monitoring of oxygen consumption}

Imaging of oxygen $\left(\mathrm{O}_{2}\right)$ consumption is characteristic of biofilm bacterial activity $[50,96]$. Transparent luminescent planar $\mathrm{O}_{2}$ optodes combined with an imaging system is suitable for early biofouling detection (Figs. S12 and S13) [50]. This detection is achieved by measuring the spatial distribution of $\mathrm{O}_{2}$ concentrations and utilization rates which is caused by biological activity inside the MFS. Biofouling development was detected in an earlier stage by the optodes than by an FCP increase over the MFS [32,50,96,98-101].

\subsubsection{Non-destructive profiling of water flow}

NMR enables to follow the evolution of biofouling by (i) the spatial biofilm distribution, (ii) the spatially resolved linear flow velocity field and (iii) displacement propagators, which are distributions of molecular displacement of a passive tracer (water) $[46,53]$. NMR has been used for MFSs and spiral-wound membrane elements (Fig. S14) [53]. Non-destructive early warning of biofouling in a commercial spiral-wound RO membrane has been demonstrated using an Earth's field (EF) NMR [102,103].

The early detection of biofouling has been demonstrated using the MFS (Fig. 13(a)) [54], the optode (Fig. 13(b)) [50], and NMR (Fig. 13(c)) [102].

\subsubsection{Non-destructive imaging system for characterization of biofilm mechanical properties}

OCT enables the assessment of the development of biofilm accumulation, morphology, and sloughing, non-destructively and with high resolution. OCT showed to be able to identify and quantify early biofilm formation [104] and the impact of permeate flux variations on the biofilm structure and membrane performance parameters [105]. 
(a)
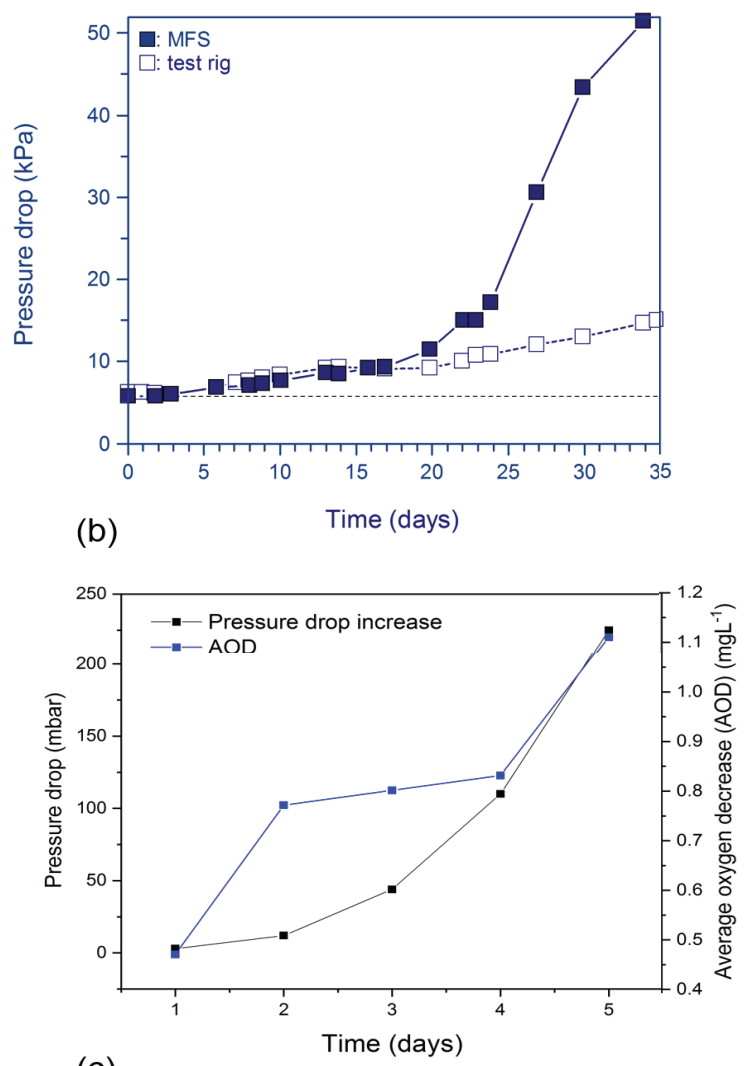

(c)

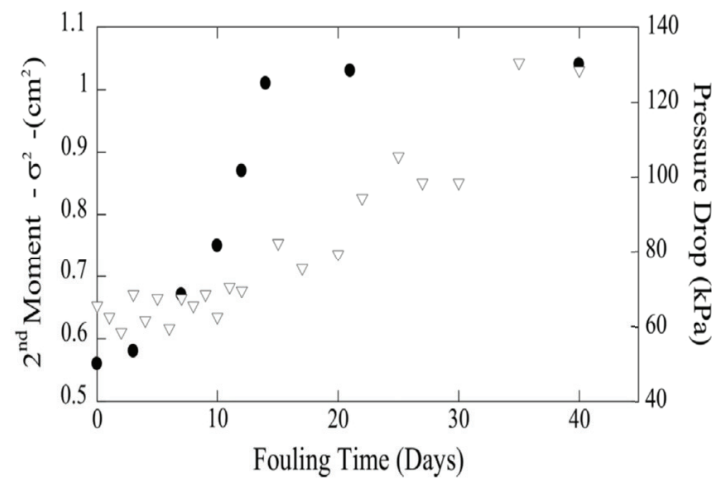

Fig. 13. Comparison of early biofouling detection methods including FCP increase in MFS, monitoring of oxygen consumption, and non-destructive analysis of velocity profiles. (a) FCP increase in time over the MFS and membrane element in the test-rig operated in parallel [4]. (b) FCP (left y-axis) and average oxygen decrease (AOD, right y-axis) of an MFS [50]. (c) The pattern of the second moment $(\bullet)$ of a fouling RO membrane, as acquired using EF-NMR along with the FCP $(\nabla)$ as a function of fouling time [103]. The oxygen sensing optode and NMR detected an earlier stage of or more sensitively biofouling than the FCP increase.

\subsubsection{Real-time spectroscopic monitoring of the fouling} components

An in-situ non-destructive early warning system to detect, quantify and analyze inorganic, organic, and biological fouling has been developed which is called "WatSup system" [106]. It allows monitoring of the FCP and on-line quantification and characterization of membrane fouling by applying fluorescence patterns, absorption, and reflection technologies.

\section{Conclusions and perspective}

This review provides a state-of-the-art overview of the development and applications of MFS. The MFS has been designed to have the same flow channel height, hydraulic behavior, and materials of membrane and spacer as spiral-wound membrane elements in practice. The MFS has proven to be a suitable tool to study biofilm processes and strategies for biofouling control. A suite of simulators has been developed as in-situ imaging tools for biofilm studies in combination with detection measures such as oxygen optode, NMR, and OCT.

Fouling development can be studied by sensitive monitoring of the FCP and visual observations through the simulator sight window. A variety of MFSs have been developed [3] for varying purposes such as for studying (i) feed spacers geometry causing variation of flow channel height in MFSs [37], (ii) the hydraulic biofilm resistance with permeate production $[107,108]$, (iii) biofilm processes and its impact on hydraulics [109], and (iv) the impact and sequence of biofouling development on membrane performance parameters including $\mathrm{FCP}$, permeate flux and salt passage in a recently developed $1 \mathrm{~m}$ long MFS (long-channel membrane test cell) with five sections over the length, enabling the measurement of permeate flux and salt passage over the test cell length [31]. This 1 meter long MFS is characterized by a more rigid structure $(4 \mathrm{~cm}$ wide membrane sheets, 24 bolts with metal support) compared with the earlier developed prototype cell, and proved to be representative for membrane modules for both flow profile and flow pressure drop relationship.

This $1 \mathrm{~m}$ long MFS with the sight window has been tested up to 15 bar [31], therefore, there is a need for the development of a high pressure simulator suitable for operation at pressure up to 80 bar representing membrane modules used in practice for seawater desalination. The next-generation of high pressure MFSs would enable the study of the effect of hydraulic pressure and concentration polarization $(\mathrm{CP})$ and advanced biofouling control strategies. The CP caused by the concentrated water constituents and fouling layer near the membrane can reduce the performance of a membrane installation. The presence of a biofilm can increase $\mathrm{CP}$, reducing the permeate flux for high salinity feed water $[28,85,89-95]$. The advanced control strategies applying physical approaches may include variation in shear, air sparging, back-washing and chemical cleaning agents separately or combined [24].

\section{Acknowledgments}

The authors would like to thank King Abdullah University of Science and Technology (KAUST) for funding support during the preparation of this manuscript. Szilard S. Bucs, Sjack van Agtmaal, Mike Johns, Einar Fridjonnson, Sarah Creber are thanked for their contribution to the studies. 


\section{References}

[1] J.S. Vrouwenvelder, S.M. Bakker, L.P. Wessels, J.A.M. van Paassen, The Membrane fouling simulator as a new tool for biofouling control of spiral-wound membranes, Desalination, 204 (2007) 170-174.

[2] J.S. Vrouwenvelder, S.A. Manolarakis, J.P. van der Hoek, J.A. van Paassen, W.G. van der Meer, J.M. van Agtmaal, H.D. Prummel, J.C. Kruithof, M.C. van Loosdrecht, Quantitative biofouling diagnosis in full scale nanofiltration and reverse osmosis installations, Water Res., 42 (2008) 4856-4868.

[3] J.S. Vrouwenvelder, C. Hinrichs, A.R. Sun, F. Royer, J.A.M. van Paassen, S.M. Bakker, W.G.J. van der Meer, J.C. Kruithof, M.C.M. van Loosdrecht, Monitoring and control of biofouling in nanofiltration and reverse osmosis membranes, Water Sci. Technol. Water Supply, 8 (2008) 449-458.

[4] J.S. Vrouwenvelder, J.A.M. van Paassen, L.P. Wessels, A.F. van Dama, S.M. Bakker, The membrane fouling simulator: a practical tool for fouling prediction and control, J. Membr. Sci., 281 (2006) 316-324.

[5] A. Siddiqui, I. Pinel, E.I. Prest, S.S. Bucs, M.C.M. van Loosdrecht, J.C. Kruithof, J.S. Vrouwenvelder, Application of DBNPA dosage for biofouling control in spiral wound membrane systems, Desal. Wat. Treat., 68 (2017) 12-22.

[6] L.N. Sim, T.H. Chong, A.H. Taheri, S.T.V. Sim, L. Lai, W.B. Krantz, A.G. Fane, A review of fouling indices and monitoring techniques for reverse osmosis, Desalination, 434 (2018) 169-188.

[7] A.J. Karabelas, M. Kostoglou, C.P. Koutsou, Modeling of spiral wound membrane desalination modules and plants - review and research priorities, Desalination, 356 (2015) 165-186.

[8] H.-C. Flemming, Mechanistic Aspects of Reverse Osmosis Membrane Biofouling and Prevention, Van Nostrand Reinhold, New York, 1993.

[9] H.F. Ridgway, A. Kelly, C. Justice, B.H. Olson, Microbial fouling of reverse-osmosis membranes used in advanced wastewater treatment technology: Chemical, bacteriological, and ultrastructural analyses, Appl. Environ. Microbiol., 45 (1983) 1066-1084.

[10] K. Tasaka, T. Katsura, H. Iwahori, Y. Kamiyama, Analysis of $\mathrm{RO}$ elements operated at more than 80 plants in Japan, Desalination, 96 (1994) 259-272.

[11] J.S. Baker, L.Y. Dudley, Biofouling in membrane systems - a review, Desalination, 118 (1998) 81-89.

[12] R. Schneider, L. Ferreira, P. Binder, E. Bejarano, K. Goes, E. Slongo, C. Machado, G. Rosa, Dynamics of organic carbon and of bacterial populations in a conventional pretreatment train of a reverse osmosis unit experiencing severe biofouling, J. Membr. Sci., 266 (2005) 18-29.

[13] H.F. Ridgway, H.F. Flemming, Membrane Biofouling, McGraw-Hill, 1996.

[14] M.A. Shannon, P.W. Bohn, M. Elimelech, J.G. Georgiadis, B.J. Marinas, A.M. Mayes, Science and technology for water purification in the coming decades, Nature, 452 (2008) 301-310.

[15] L.N. Sim, Z.J. Wang, J. Gu, H.G.L. Coster, A.G. Fane, Detection of reverse osmosis membrane fouling with silica, bovine serum albumin and their mixture using in-situ electrical impedance spectroscopy, J. Membr. Sci., 443 (2013) 45-53.

[16] A. Al Ashhab, M. Herzberg, O. Gillor, Biofouling of reverseosmosis membranes during tertiary wastewater desalination: microbial community composition, Water Res., 50 (2014) 341-349.

[17] O. Habimana, A.J.C. Semião, E. Casey, The role of cell-surface interactions in bacterial initial adhesion and consequent biofilm formation on nanofiltration/reverse osmosis membranes, J. Membr. Sci., 454 (2014) 82-96.

[18] W. Ying, V. Gitis, J. Lee, M. Herzberg, Effects of shear rate on biofouling of reverse osmosis membrane during tertiary wastewater desalination, J. Membr. Sci., 427 (2013) 390-398.

[19] M.T. Khan, M. Busch, V.G. Molina, A.H. Emwas, C. Aubry, J.P. Croue, How different is the composition of the fouling layer of wastewater reuse and seawater desalination $\mathrm{RO}$ membranes?, Water Res., 59 (2014) 271-282.
[20] M. Ben-Sasson, X. Lu, E. Bar-Zeev, K.R. Zodrow, S. Nejati, G. Qi, E.P. Giannelis, M. Elimelech, In situ formation of silver nanoparticles on thin-film composite reverse osmosis membranes for biofouling mitigation, Water Res., 62 (2014) 260-270.

[21] J.B. Andersen, A. Heydorn, M. Hentzer, L. Eberl, O. Geisenberger, B.B. Christensen, S. Molin, M. Givskov, Gfpbased $\mathrm{N}$-acyl homoserine-lactone sensor systems for detection of bacterial communication, Appl. Environ. Microbiol., 67 (2001) 575-585.

[22] M.S. Mauter, A. Fait, M. Elimelech, M. Herzberg, Surface cell density effects on Escherichia coli gene expression during cell attachment, Environ. Sci. Technol., 47 (2013) 6223-6230.

[23] H.C. Flemming, Biofouling in water systems--cases, causes and countermeasures, Appl. Microbiol. Biotechnol., 59 (2002) 629-640.

[24] S.S. Bucs, N. Farhat, J.C. Kruithof, C. Picioreanu, M.C.M. van Loosdrecht, J.S. Vrouwenvelder, Review on strategies for biofouling mitigation in spiral wound membrane systems, Desalination, 434 (2018) 189-197.

[25] H.-C. Flemming, A. Tamachkiarowa, J. Klahre, J. Schmitt, Monitoring of fouling and biofouling in technical systems, Water Sci. Technol., 38 (1998) 291-298.

[26] H.-C. Flemming, Role and levels of real-time monitoring for successful anti-fouling strategies - an overview, Water Sci. Technol., 47 (2003) 1-8.

[27] S.S. Bucs, N. Farhat, A. Siddiqui, R. Valladares Linares, A. Radu, J.C. Kruithof, J.S. Vrouwenvelder, Development of a setup to enable stable and accurate flow conditions for membrane biofouling studies, Desal. Wat. Treat., 57 (2015) 12893-12901.

[28] S.S. Bucs, R. Valladares Linares, M.C.M. van Loosdrecht, J.C. Kruithof, J.S. Vrouwenvelder, Impact of organic nutrient load on biomass accumulation, feed channel pressure drop increase and permeate flux decline in membrane systems, Water Res., 67 (2014) 227-242.

[29] G. Massons-Gassol, G. Gilabert-Oriol, J. Johnson, T. Arrowood, Comparing biofouling development in membrane fouling simulators and spiral-wound reverse osmosis elements using river water and municipal wastewater, Ind. Eng. Chem. Res., 56 (2017) 11628-11633.

[30] H. Sanawar, A. Siddiqui, S.S. Bucs, N.M. Farhat, M.C.M. van Loosdrecht, J.C. Kruithof, J.S. Vrouwenvelder, Applicability of short-term accelerated biofouling studies to predict longterm biofouling accumulation in reverse osmosis membrane systems, Desal. Wat. Treat., 97 (2017) 72-78.

[31] N. Siebdrath, W. Ding, E. Pietsch, J. Kruithof, W. Uhl, J.S. Vrouwenvelder, Construction and validation of a longchannel membrane test cell for representative monitoring of performance and characterization of fouling over the length of spiral-wound membrane modules, Desal. Wat. Treat., 89 (2017) 1-16.

[32] M.Staal, N.Farhat, M.C.M. van Loosdrecht, J.S. Vrouwenvelder, Biofouling patterns in spacer filled channels: High resolution imaging for characterization of heterogeneous biofilms, Desal. Wat. Treat., 80 (2017) 1-10.

[33] J.S. Vrouwenvelder, S.M. Bakker, M. Cauchard, R. Le Grand, M. Apacandié, M. Idrissi, S. Lagrave, L.P. Wessels, J.A.M. van Paassen, J.C. Kruithof, M.C.M. van Loosdrecht, The membrane fouling simulator: a suitable tool for prediction and characterisation of membrane fouling, Water Sci. Technol., 55 (2007) 197.

[34] J.S. Vrouwenvelder, J. Buiter, M. Riviere, W.G.J. van der Meer, M.C.M. van Loosdrecht, J.C. Kruithof, Impact of flow regime on pressure drop increase and biomass accumulation and morphology in membrane systems, Water Res., 44 (2010) 689-702.

[35] J.S. Vrouwenvelder, C. Hinrichs, W.G.J. van der Meer, M.C.M. van Loosdrecht, J.C. Kruithof, Pressure drop increase by biofilm accumulation in spiral wound $\mathrm{RO}$ and NF membrane systems: role of substrate concentration, flow velocity, substrate load and flow direction, Biofouling, 25 (2009) 543-555. 
[36] J.S. Vrouwenvelder, J.A.M. van Paassen, J.M.C. van Agtmaal, M.C.M. van Loosdrecht, J.C. Kruithof, A critical flux to avoid biofouling of spiral wound nanofiltration and reverse osmosis membranes: fact or fiction?, J. Membr. Sci., 326 (2009) 36-44.

[37] P.A. Araújo, J.C. Kruithof, M.C.M. van Loosdrecht, J.S Vrouwenvelder, The potential of standard and modified feed spacers for biofouling control, J. Membr. Sci., 403-404 (2012) 58-70.

[38] P.A. Araújo, D.J. Miller, P.B. Correia, M.C.M. van Loosdrecht, J.C. Kruithof, B.D. Freeman, D.R. Paul, J.S. Vrouwenvelder, Impact of feed spacer and membrane modification by hydrophilic, bactericidal and biocidal coating on biofouling control, Desalination, 295 (2012) 1-10.

[39] S.S. Bucs, R.V. Linares, N. Farhat, A. Matin, Z. Khan, M.C.M. van Loosdrecht, R. Yang, M. Wang, K.K. Gleason, J.C. Kruithof, J.S. Vrouwenvelder, Coating of reverse osmosis membranes with amphiphilic copolymers for biofouling control, Desal. Wat. Treat., 68 (2017) 1-11.

[40] S.A. Creber, J.S. Vrouwenvelder, M.C.M. van Loosdrecht, M.L. Johns, Chemical cleaning of biofouling in reverse osmosis membranes evaluated using magnetic resonance imaging, J. Membr. Sci., 362 (2010) 202-210.

[41] J. Duiven, B. Rietman, W. van de Ven, Application of the membrane fouling simulator to determine biofouling potentia of antiscalants in membrane filtration, J. Water Supply Res. Technol., 59 (2010) 111-119.

[42] D.J. Miller, P.A. Araújo, P.B. Correia, M.M. Ramsey, J.C. Kruithof, M.C.M. van Loosdrecht, B.D. Freeman, D.R. Paul, M. Whiteley, J.S. Vrouwenvelder, Short-term adhesion and longterm biofouling testing of polydopamine and poly(ethylene glycol) surface modifications of membranes and feed spacers for biofouling control, Water Res., 46 (2012) 3737-3753.

[43] A. Siddiqui, N. Farhat, S.S. Bucs, R.V. Linares, C. Picioreanu, J.C. Kruithof, M.C.M. van Loosdrecht, J. Kidwell, J.S Vrouwenvelder, Development and characterization of 3D-printed feed spacers for spiral wound membrane systems, Water Res., 91 (2016) 55-67.

[44] A. Siddiqui, S. Lehmann, S.S. Bucs, M. Fresquet, L. Fel, E.I.E.C. Prest, J. Ogier, C. Schellenberg, M.C.M. van Loosdrecht, J.C. Kruithof, J.S. Vrouwenvelder, Predicting the impact of feed spacer modification on biofouling by hydraulic characterization and biofouling studies in membrane fouling simulators, Water Res., 110 (2017) 281-287.

[45] J.S. Vrouwenvelder, F. Beyer, K. Dahmani, N. Hasan, G. Galjaard, J.C. Kruithof, M.C.M. van Loosdrecht, Phosphate limitation to control biofouling, Water Res., 44 (2010) 3454-3466.

[46] J.S. Vrouwenvelder, D.A. Graf von der Schulenburg, J.C. Kruithof, M.L. Johns, M.C.M. van Loosdrecht, Biofouling of spiral-wound nanofiltration and reverse osmosis membranes: a feed spacer problem, Water Res., 43 (2009) 583-594.

[47] J.S. Vrouwenvelder, J.C. Kruithof, M.C.M. van Loosdrecht, Integrated approach for biofouling control, Water. Sci. Technol., 62 (2010) 2477-2490.

[48] J.S. Vrouwenvelder, C. Picioreanu, J.C. Kruithof, M.C.M. van Loosdrecht, Biofouling in spiral wound membrane systems: three-dimensional CFD model based evaluation of experimental data, J. Membr. Sci., 346 (2010) 71-85.

[49] J.S. Vrouwenvelder, M.C.M. van Loosdrecht, J.C. Kruithof A novel scenario for biofouling control of spiral wound membrane systems, Water Res., 45 (2011) 3890-3898.

[50] N.M. Farhat, M. Staal, A. Siddiqui, S.M. Borisov, S.S. Bucs, J.S Vrouwenvelder, Early non-destructive biofouling detection and spatial distribution: application of oxygen sensing optodes, Water Res., 83 (2015) 10-20.

[51] L. Fortunato, S.S. Bucs, R.V. Linares, C. Cali, J.S. Vrouwenvelder, T. Leiknes, Spatially-resolved in-situ quantification of biofouling using optical coherence tomography (OCT) and 3D image analysis in a spacer filled channel, J. Membr. Sci., 524 (2017) 673-681.

[52] L. Fortunato, T. Leiknes, In-situ biofouling assessment in spacer filled channels using optical coherence tomography (OCT): 3D biofilm thickness mapping, Bioresour. Technol., 229 (2017) 231-235.
[53] D.A. Graf von der Schulenburg, J.S. Vrouwenvelder, S.A Creber, M.C.M. van Loosdrecht, M.L. Johns, Nuclear magnetic resonance microscopy studies of membrane biofouling, J. Membr. Sci., 323 (2008) 37-44.

[54] J.S. Vrouwenvelder, M.C.M. van Loosdrecht, J.C. Kruithof, Early warning of biofouling in spiral wound nanofiltration and reverse osmosis membranes, Desalination, 265 (2011) 206-212.

[55] J.S. Vrouwenvelder, J.A.M. van Paassen, J.C. Kruithof, M.C.M. van Loosdrecht, Sensitive pressure drop measurements of individual lead membrane elements for accurate early biofouling detection, J. Membr. Sci., 338 (2009) 92-99.

[56] G. Schock, A. Miquel, Mass transfer and pressure loss in spiral wound modules, Desalination, 64 (1987) 339-352.

[57] S.S. Bucs, N. Farhat, A. Siddiqui, R.V. Linares, A. Radu, J.C. Kruithof, J.S. Vrouwenvelder, Development of a setup to enable stable and accurate flow conditions for membrane biofouling studies, Desal. Wat. Treat., 57 (2016) 12893-12901.

[58] M. Kostoglou, A.J. Karabelas, Mathematical analysis of the meso-scale flow field in spiral-wound membrane modules, Ind. Eng. Chem. Res., 50 (2011) 4653-4666.

[59] L.P. Wessels, S.M. Bakker, J.S. Vrouwenvelder, J.A.M. Paassen, Membrane Fouling Monitor, Dutch patent NL 1028474, 11 September, The Netherlands, 2006.

[60] H. Sanawar, A. Siddiqui, Sz. S. Bucs, N.M. Farhat, M.C.M. van Loosdrecht, J.C. Kruithof, J.S. Vrouwenvelder, Applicability of short-term accelerated biofouling studies to predict longterm biofouling accumulation in reverse osmosis membrane systems, Desal. Wat. Treat., 97 (2017) 72-78.

[61] C. Dreszer, H.C. Flemming, A.D. Wexler, A. Zwijnenburg, J.C. Kruithof, J.S. Vrouwenvelder, Development and testing of a transparent membrane biofouling monitor, Desal. Wat. Treat., 52 (2014) 1807-1819.

[62] W.A.M. Hijnen, D. Biraud, E.R. Cornelissen, D. van Der Kooij, Threshold concentration of easily assimilable organic carbon in feedwater for biofouling of spiral-wound membranes, Environ. Sci. Technol., 43 (2009) 4890-4895.

[63] T. Griebe, H.-C. Flemming, Biocide-free antifouling strategy to protect $\mathrm{RO}$ membranes from biofouling, Desalination, 118 (1998) 153-159.

[64] P.A. Alphenaar, R. Sleyster, P. de Reuver, G.-J. Ligthart, G. Lettinga, Phosphorus requirement in high-rate anaerobic wastewater treatment, Water Res., 27 (1993) 749-756.

[65] P.J. Harrison, M.H. Hu, Y.P. Yang, X. Lu, Phosphate limitation in estuarine and coastal waters of China, J. Exp. Mar. Biol. Ecol., 140 (1990) 79-87.

[66] E. van Donk, L.R. Mur, J. Ringelberg, A study of phosphate limitation in Lake Maarsseveen: phosphate uptake kinetics versus bioassays, Hydrobiologia, 188 (1989) 201-209.

[67] T. Toolan, J.D. Wehr, S. Findlay, Inorganic phosphorus stimulation of bacterioplankton production in a mesoeutrophic lake, Appl. Environ. Microbiol., 57 (1991) 2074-2078.

[68] A. Pettersson, P. Blomqvist, Bioassay for phosphate demand in phytoplankton from acidified lakes: Lake Njupfatet, an example of phosphate deficiency induced by liming, Hydrobiologia, 246 (1992) 99-110.

[69] M.N. Mohamed, J.R. Lawrence, R.D. Robarts, Phosphorus limitation of heterotrophic biofilms from the Fraser River, British Columbia, and the effect of pulp mill effluent, Microb. Ecol., 36 (1998) 121-130.

[70] T. Zohary, B. Herut, M.D. Krom, R.F.C. Mantoura, P. Pitta S. Psarra, F. Rassoulzadegan, N. Stambler, T. Tanaka, T.F. Thingstad, E.M.S. Woodward, P-limited bacteria but $\mathrm{N}$ and $\mathrm{P}$ co-limited phytoplankton in the Eastern Mediterranean-a microcosm experiment, Deep Sea Res. Part 2 Top. Stud. Oceanogr., 52 (2005) 3011-3023.

[71] I.T. Miettinen, T. Vartiainen, P.J. Martikainen, Phosphorus and bacterial growth in drinking water, Appl. Environ. Microbiol., 63 (1997) 3242-3245.

[72] E. Torvinen, M.J. Lehtola, P.J. Martikainen, I.T. Miettinen, Survival of Mycobacterium avium in drinking water biofilms as affected by water flow velocity, availability of phosphorus, and temperature, Appl. Environ. Microbiol., 73 (2007) 6201-6207. 
[73] S. Kasahara, K. Maeda, M. Ishikawa, Influence of phosphorus on biofilm accumulation in drinking water distribution systems, Water Sci. Technol. Water Supply, 4 (2005) 389-398.

[74] M.J. Lehtola, I.T. Miettinen, T. Vartiainen, P.J. Martikainen, Changes in content of microbially available phosphorus, assimilable organic carbon and microbial growth potential during drinking water treatment processes, Water Res., 36 (2002) 3681-3690.

[75] M.J. Lehtola, T. Juhna, I.T. Miettinen, T. Vartiainen, P.J. Martikainen, Formation of biofilms in drinking water distribution networks, a case study in two cities in Finland and Latvia, J. Ind. Microbiol. Biotechnol., 31 (2004) 489-494.

[76] G. Tchobanoglous, F.L. Burton, H.D. Stensel, Wastewater Engineering: Treatment and Reuse, 4th ed., McGraw-Hill, New York, 2003.

[77] W. Maher, L. Woo, Procedures for the storage and digestion of natural waters for the determination of filterable reactive phosphorus, total filterable phosphorus and total phosphorus, Anal. Chim. Acta, 375 (1998) 5-47.

[78] J.S. Vrouwenvelder, S.A. Manolarakis, H.R. Veenendaal, D. van der Kooij, Biofouling potential of chemicals used for scale control in RO and NF membranes, Desalination, 132 (2000) $1-10$.

[79] R.C.M. Jong, J. Duiven, G.G. Terhorst, K.J. Baas, Implementation research of new phosphorus free antiscalant at an aerobic ground water RO plant, Desal. Wat. Treat., 51 (2013) 5021-5025.

[80] R.P. Carnahan, L. Bolin, W. Suratt, Biofouling of PVD-1 reverse osmosis elements in the water treatment plant of the city of Dunedin, Florida, Desalination, 102 (1995) 235-244.

[81] J.S. Vrouwenvelder, J.A.M. van Paassen, H.C. Folmer, Jan A.M.H. Hofman, M.M. Nederlof, D. van der Kooij, Biofouling of membranes for drinking water production, Desalination, 118 (1998) 157-166.

[82] M. Uchymiak, A.R. Bartman, N. Daltrophe, M. Weissman, J. Gilron, P.D. Christofides, W.J. Kaiser, Y. Cohen, Brackish water reverse osmosis (BWRO) operation in feed flow reversal mode using an ex situ scale observation detector (EXSOD), J. Membr. Sci., 341 (2009) 60-66.

[83] E.R. Cornelissen, L. Rebour, D. van der Kooij, L.P. Wessels, Optimization of air/water cleaning (AWC) in spiral wound elements, Desalination, 236 (2009) 266-272.

[84] E.R. Cornelissen, J.S. Vrouwenvelder, S.G.J. Heijman, X.D. Viallefont, D. van der Kooij, L.P. Wessels, Periodic air/water cleaning for control of biofouling in spiral wound membrane elements, J. Membr. Sci., 287 (2007) 94-101.

[85] A.I. Radu, J.S. Vrouwenvelder, M.C.M. van Loosdrecht, C. Picioreanu, Effect of flow velocity, substrate concentration and hydraulic cleaning on biofouling of reverse osmosis feed channels, Chem. Eng. J., 188 (2012) 30-39.

[86] A.I. Radu, M.S.H. van Steen, J.S. Vrouwenvelder, M.C.M. van Loosdrecht, C. Picioreanu, Spacer geometry and particle deposition in spiral wound membrane feed channels, Water Res., 64 (2014) 160-176.

[87] C. Picioreanu, J.S. Vrouwenvelder, M.C.M. van Loosdrecht, Three-dimensional modeling of biofouling and fluid dynamics in feed spacer channels of membrane devices, J. Membr. Sci., 345 (2009) 340-354.

[88] S.A. Creber, T.R.R. Pintelon, D.A. Graf von der Schulenburg, J.S. Vrouwenvelder, M.C.M. van Loosdrecht, M.L. Johns, Magnetic resonance imaging and 3D simulation studies of biofilm accumulation and cleaning on reverse osmosis membranes, Food Bioprod. Process, 88 (2010) 401-408.

[89] T.H. Chong, F.S. Wong, A.G. Fane, Implications of critical flux and cake enhanced osmotic pressure (CEOP) on colloidal fouling in reverse osmosis: experimental observations, J. Membr. Sci., 314 (2008) 101-111.

[90] T.H. Chong, F.S. Wong, A.G. Fane, The effect of imposed flux on biofouling in reverse osmosis: role of concentration polarisation and biofilm enhanced osmotic pressure phenomena, J. Membr. Sci., 325 (2008) 840-850.

[91] M. Herzberg, M. Elimelech, Biofouling of reverse osmosis membranes: role of biofilm-enhanced osmotic pressure, J. Membr. Sci., 295 (2007) 11-20.
[92] M. Herzberg, M. Elimelech, Physiology and genetic traits of reverse osmosis membrane biofilms: a case study with Pseudomonas aeruginosa, ISME J., 2 (2008) 180-194.

[93] A.I. Radu, J.S. Vrouwenvelder, M.C.M. van Loosdrecht, C. Picioreanu, Modeling the effect of biofilm formation on reverse osmosis performance: flux, feed channel pressure drop and solute passage, J. Membr. Sci., 365 (2010) 1-15.

[94] A.I. Radu, J.S. Vrouwenvelder, M.C.M. van Loosdrecht, C. Picioreanu, Biofouling in membrane devices treating water with different salinities: a modeling study, Desal. Wat. Treat., 34 (2011) 284-289.

[95] M. Amokrane, D. Sadaoui, C.P. Koutsou, A.J. Karabelas, M. Dudeck, A study of flow field and concentration polarization evolution in membrane channels with two-dimensional spacers during water desalination, J. Membr. Sci., 477 (2015) 139-150.

[96] R.V. Linares, L. Fortunato, N.M. Farhat, S.S. Bucs, M. Staal, E.O. Fridjonsson, M.L. Johns, J.S. Vrouwenvelder, T. Leiknes, Minireview: novel non-destructive in situ biofilm characterization techniques in membrane systems, Desal. Wat. Treat., 57 (2016) 22894-22901.

[97] S. West, M. Wagner, C. Engelke, H. Horn, Optical coherence tomography for the in situ three-dimensional visualization and quantification of feed spacer channel fouling in reverse osmosis membrane modules, J. Membr. Sci., 498 (2016) 345-352.

[98] N.M. Farhat, M. Staal, S.S. Bucs, M.C.M. van Loosdrecht, J.S. Vrouwenvelder, Spatial heterogeneity of biofouling under different cross-flow velocities in reverse osmosis membrane systems, J. Membr. Sci., 520 (2016) 964-971.

[99] N.M. Farhat, J.S. Vrouwenvelder, M.C.M. van Loosdrecht, S.S. Bucs, M. Staal, Effect of water temperature on biofouling development in reverse osmosis membrane systems, Water Res., 103 (2016) 149-159.

[100] E.I. Prest, M. Staal, M. Kühl, M.C.M. van Loosdrecht, J.S. Vrouwenvelder, Quantitative measurement and visualization of biofilm $\mathrm{O}_{2}$ consumption rates in membrane filtration systems, J. Membr. Sci., 392 (2012) 66-75.

[101] M. Staal, E.I. Prest, J.S. Vrouwenvelder, L.F. Rickelt, M. Kühl, A simple optode based method for imaging $\mathrm{O}_{2}$ distribution and dynamics in tap water biofilms, Water Res., 45 (2011) 5027-5037.

[102] E.O. Fridjonsson, S.J. Vogt, J.S. Vrouwenvelder, M.L. Johns, Early non-destructive biofouling detection in spiral wound RO membranes using a mobile earth's field NMR, J. Membr. Sci., 489 (2015) 227-236.

[103] E.O. Fridjonsson, S.A. Creber, J.S. Vrouwenvelder, M.L. Johns, Magnetic resonance signal moment determination using the earth's magnetic field, J. Magn. Reson., 252 (2015) 145-150.

[104] C. Dreszer, A.D. Wexler, S. Drusova, T. Overdijk, A. Zwijnenburg, H.C. Flemming, J.C. Kruithof, J.S. Vrouwenvelder, In-situ biofilm characterization in membrane systems using optical coherence tomography: formation, structure, detachment and impact of flux change, Water Res., 67 (2014) 243-254.

[105] R.V. Linares, A.D. Wexler, S.S. Bucs, C. Dreszer, A. Zwijnenburg, H.C. Flemming, J.C. Kruithof, J.S. Vrouwenvelder, Compaction and relaxation of biofilms, Desal. Wat. Treat., 57 (2015) 12902-12914.

[106] S.S. Bucs, S.T.L. Hekkert, M.J. Staal, J.S. Vrouwenvelder, In-Line Quantification and Characterization of Membrane Fouling, U.S. Patent Application 20170363535, 21 December, USA, 2017.

[107] C. Dreszer, J.S. Vrouwenvelder, A.H. Paulitsch-Fuchs, A. Zwijnenburg, J.C. Kruithof, H.C. Flemming, Hydraulic resistance of biofilms, J. Membr. Sci., 429 (2013) 436-447.

[108] C. Dreszer, H.C. Flemming, A. Zwijnenburg, J.C. Kruithof, J.S. Vrouwenvelder, Impact of biofilm accumulation on transmembrane and feed channel pressure drop: effects of crossflow velocity, feed spacer and biodegradable nutrient, Water Res., 50 (2014) 200-211.

[109] S.S. Bucs, R.V. Linares, J.O. Marston, A.I. Radu, J.S. Vrouwenvelder, C. Picioreanu, Experimental and numerical characterization of the water flow in spacer-filled channels of spiral-wound membranes, Water Res., 87 (2015) 299-310. 


\section{Supplementary material}

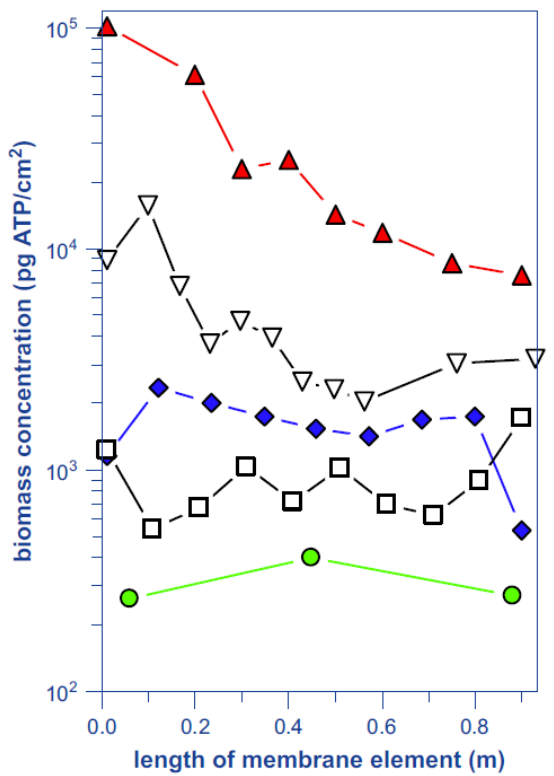

Fig. S1. Distribution of biomass (adenosine triphosphate [ATP]) concentration over the length of lead membrane elements taken from membrane installations with differences in feed channel pressure drop (FCP) increase $(\boldsymbol{\Delta}=300 \% ; \nabla=100 \%$; $\square$, $\bullet=\leq 10 \%$ ). Each marker represents a lead membrane element from one of the tested membrane installations. Severely fouled lead membranes showed high biomass concentrations that decreased over the element length and less fouled lead membranes had lower biomass concentrations that were equally distributed over the membrane element length [2].

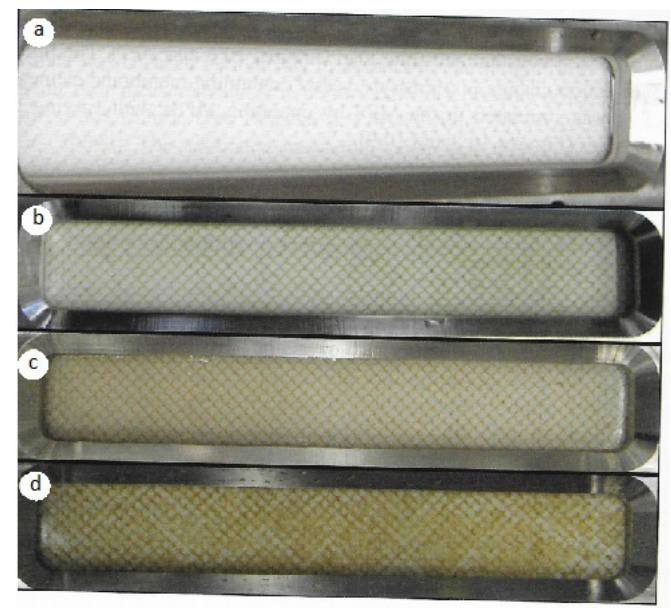

Fig. S2. Visual observations of the feed spacer and membrane in the MFS supplied 0,100, 200 and $400 \mu \mathrm{g} C / \mathrm{L}$ as acetate carbon (a, b, c and d) after $13 \mathrm{~d}$ of operation. The sight glass of the monitor was used for visual observations during operation of the MFS [35].
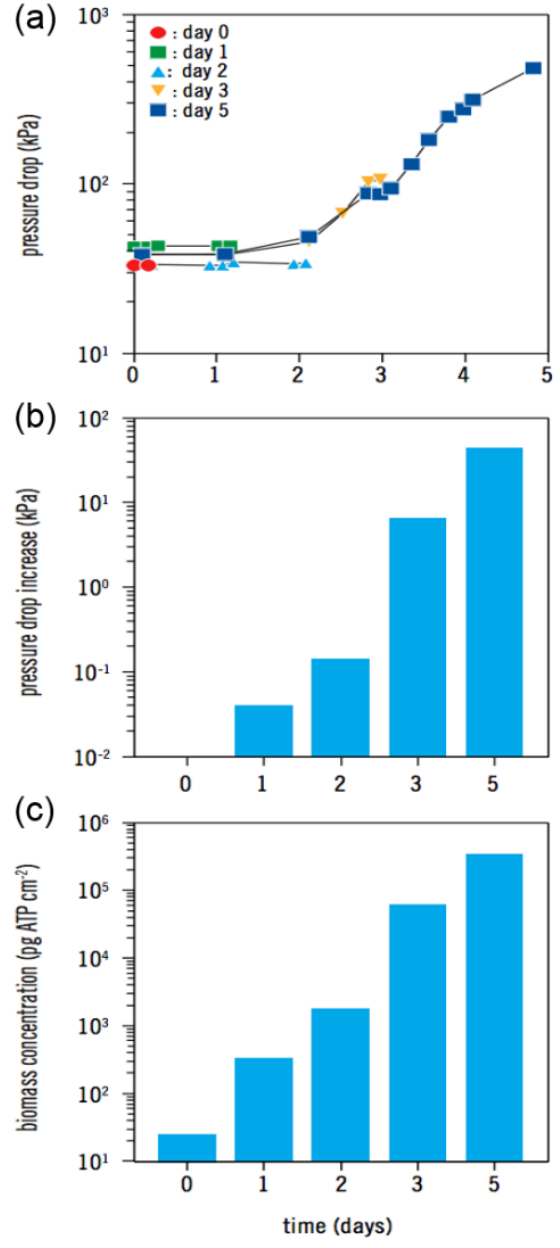

Fig. S3. (a) Measured FCP in time, (b) FCP increase and (c) biomass accumulation in MFS operated in parallel under identical conditions after $0,1,2,3$, and $5 \mathrm{~d}$. Note the logarithmic scale in (b) and (c). The nutrient concentration in the feed water was $0.60 \mathrm{mg}$ acetate $\mathrm{C} / \mathrm{L}$ and linear flow velocity in the monitors was $0.16 \mathrm{~m} / \mathrm{s}$ [48]. 

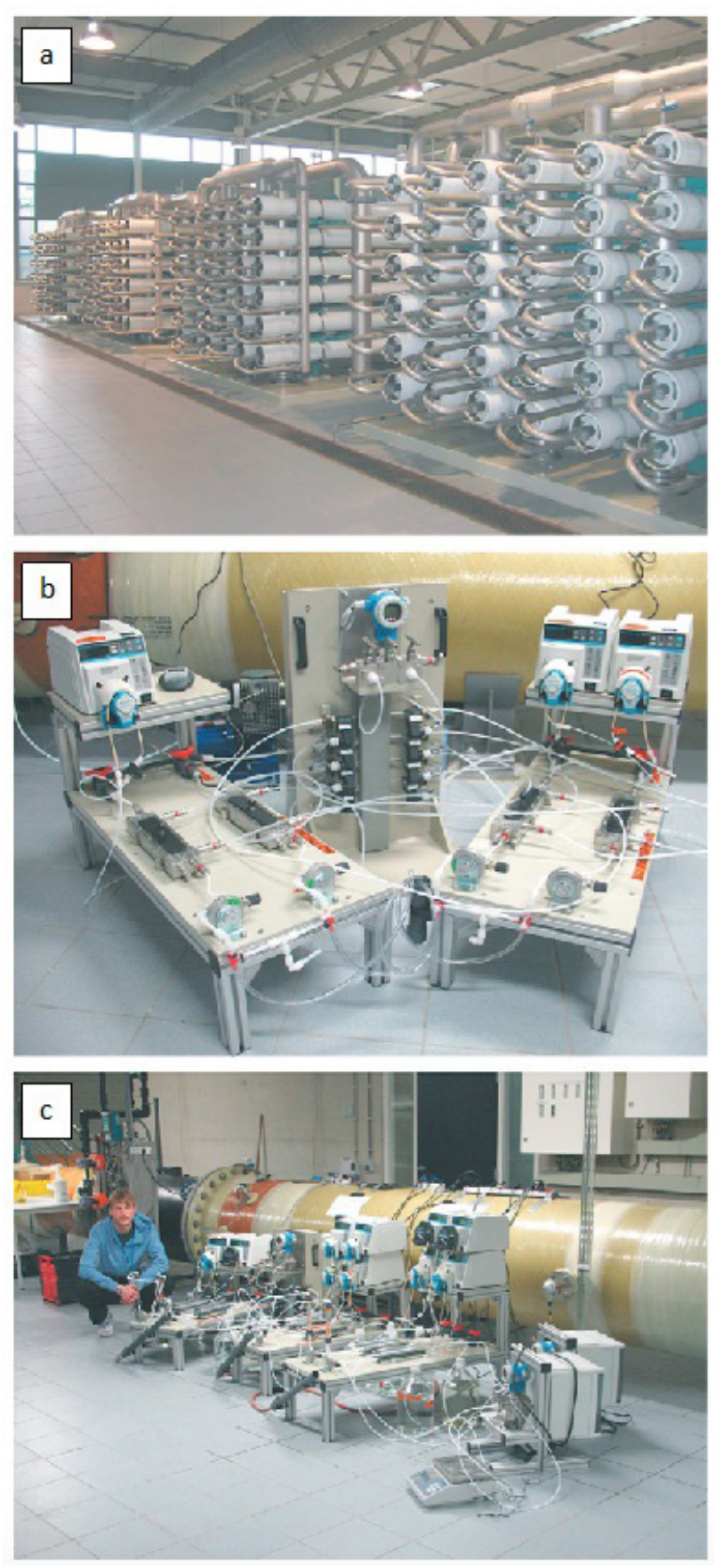

Fig. S4. (a) RO installation and experimental set-up consisting of in parallel installed monitors and (b) differential pressure transmitter during the proof of principle study and (c) anti-scalant dosage. FCP data were accessed using a modem. The horizontal tube on the background of (b) and (c) is the RO feed water pipe (Ø $1.0 \mathrm{~m})$ [45].
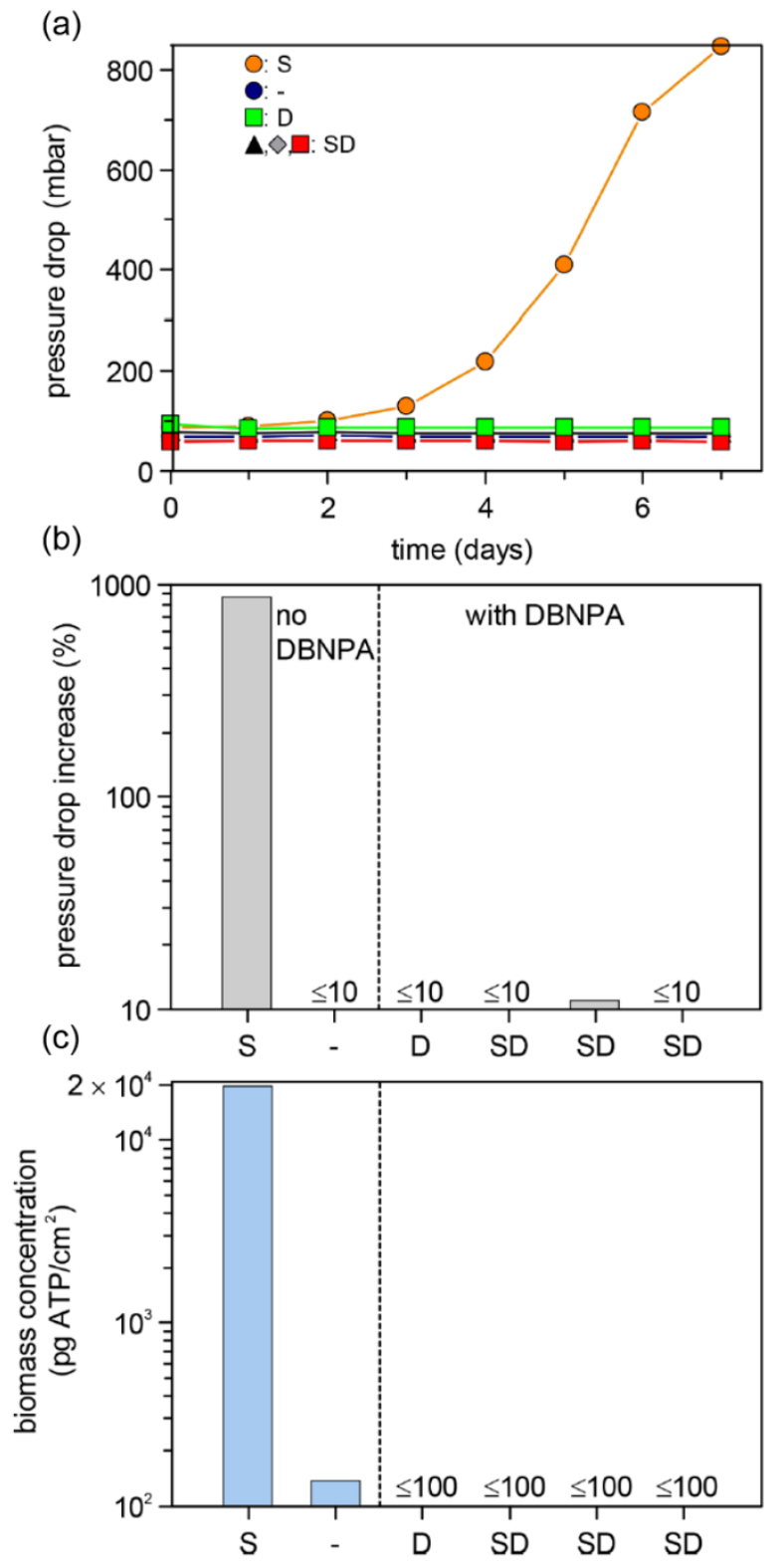

Fig. S5. DBNPA dosage (1 $\mathrm{mg} / \mathrm{L})$ to prevent biofouling. (a) FCP in time, (b) FCP increase and (c) accumulated biomass concentration in MFSs. Feed water of all MFSs was supplemented with biodegradable substrate $(500 \mu \mathrm{g} \mathrm{C} / \mathrm{L})$ from day 0 (except- and D). DBNPA was continuously dosed to the feed water (1 mg DBNPA/L) of all MFSs except - and S. S, positive control without dosage of DBNPA; D, does DBNPA only; SD, continuous dosage of DBNPA to feed water $(1 \mathrm{mg} / \mathrm{L})$ is effective for preventive biofouling control [5]. 
(a)

(b)
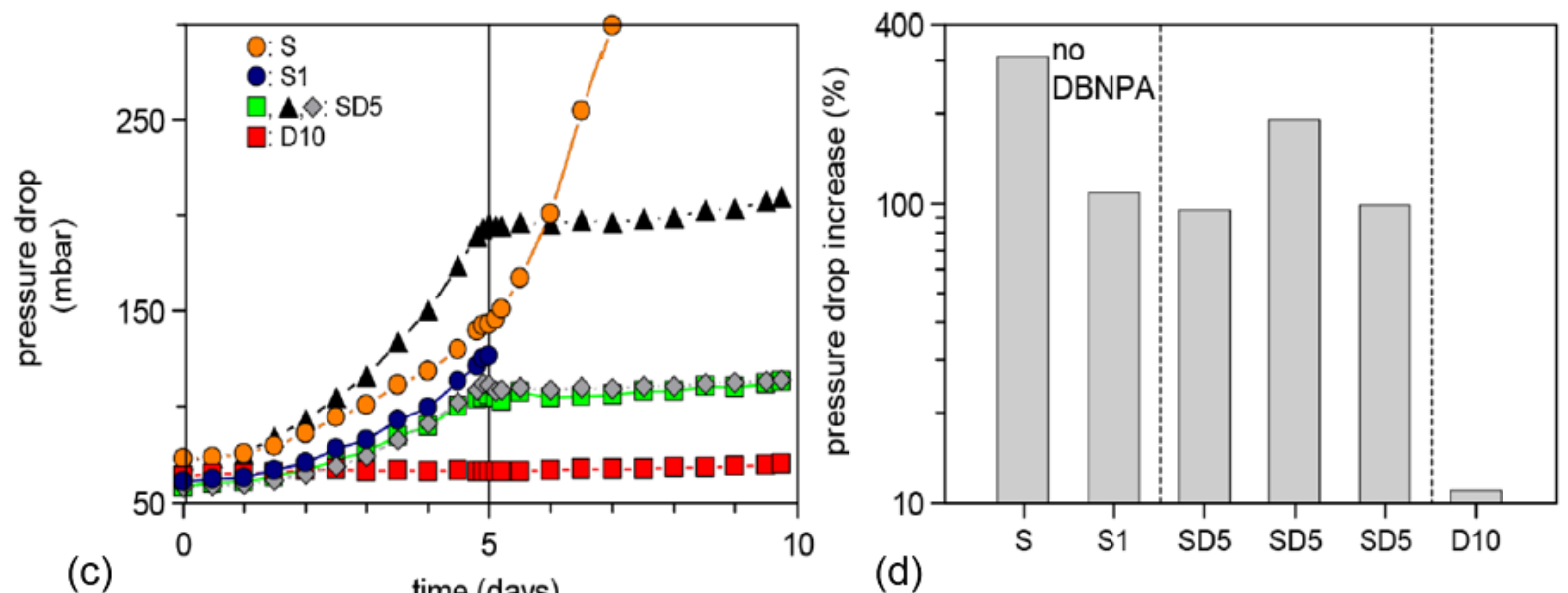

(d)
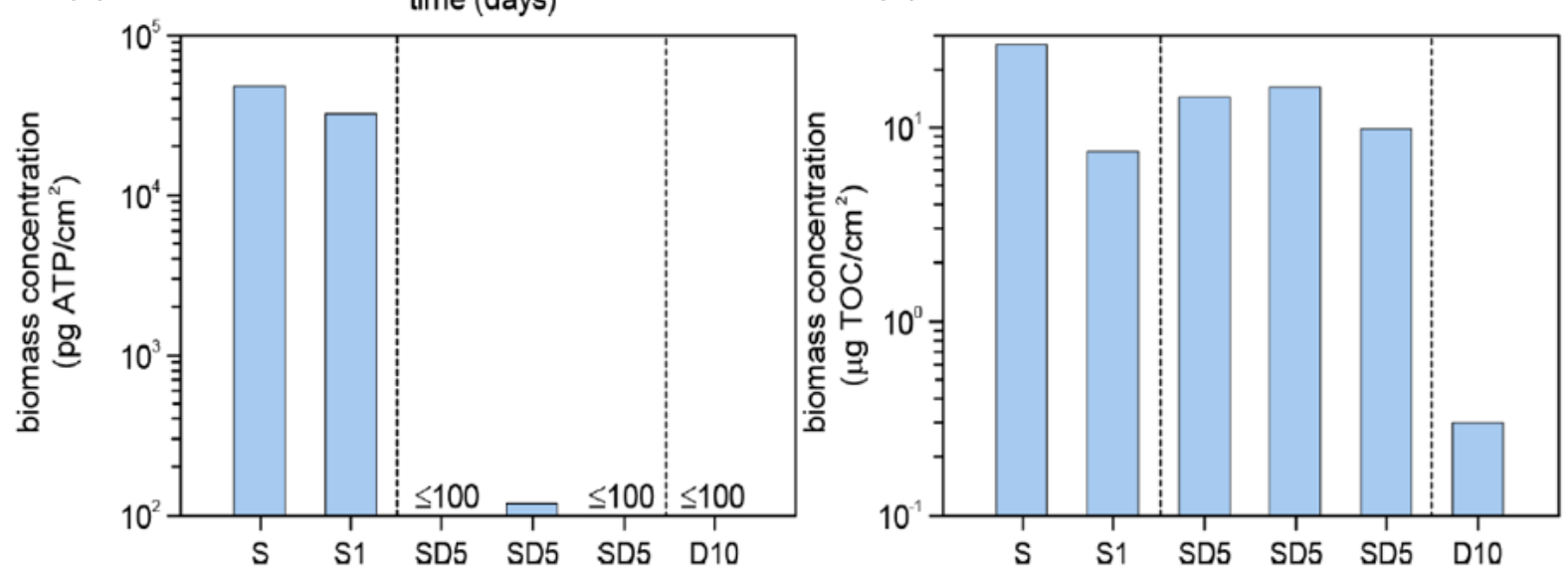

Fig. S6. DBNPA dosage (20 mg/L) to cure a biofouled membrane system. (a) FCP increase in time, (b) FCP increase and accumulated biomass concentration (c) ATP and (d) TOC in MFSs. Feed water of all MFSs was supplemented with biodegradable substrate (200 $\mu \mathrm{g}$ $\mathrm{C} / \mathrm{L}$ ) from day 0. DBNPA was continuously dosed to the feed water $(20 \mathrm{mg} / \mathrm{L}$ ) of MFSs from day 5 (SD5). Note that $\mathrm{S}$ (positive control; MFS with substrate only), S1 (operate MFS until the start of DBNPA dosage) and D10 (negative control; MFS with DBNPA dosage only) are controls. Continuous DBNPA dosage $(20 \mathrm{mg} / \mathrm{L})$ is not effective for curative biofouling control [5]. 


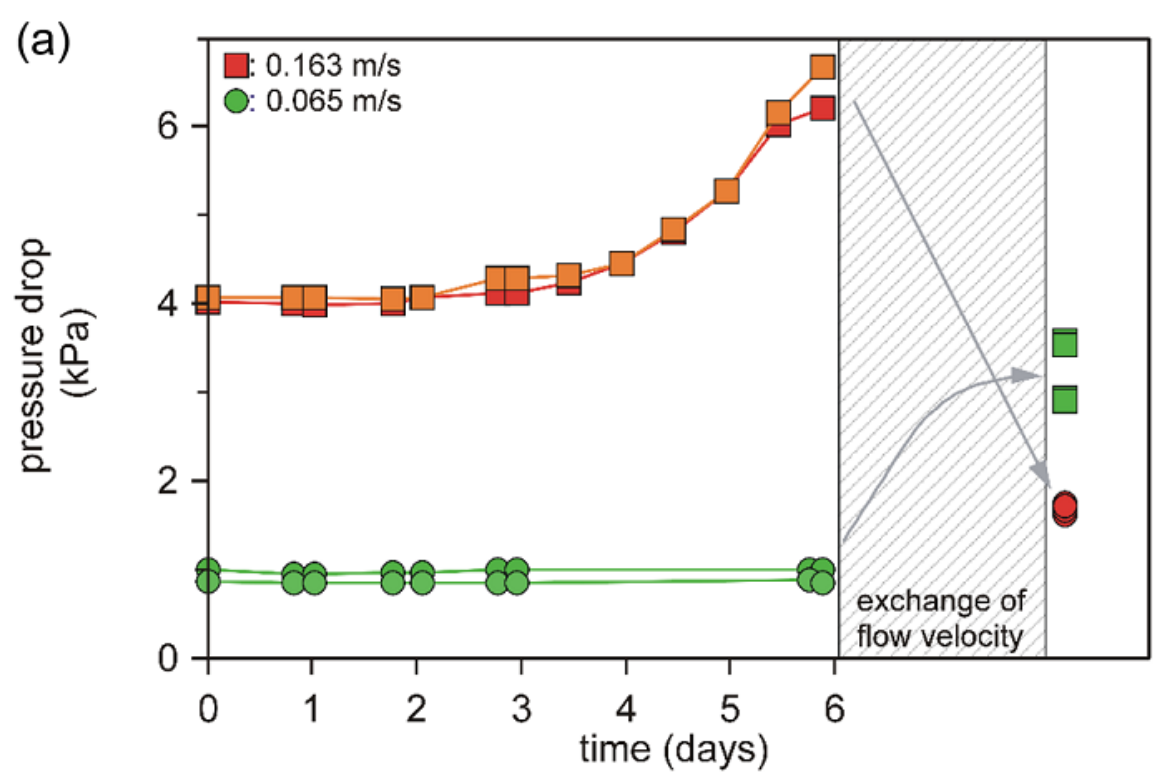

(b)

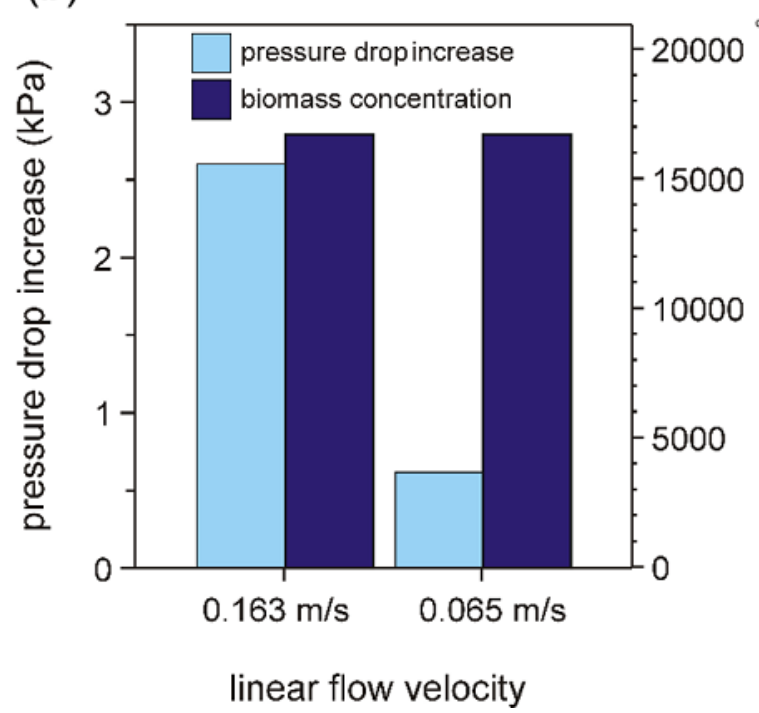

(c)

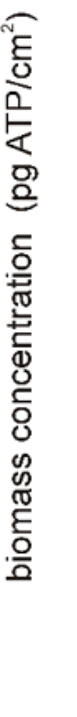

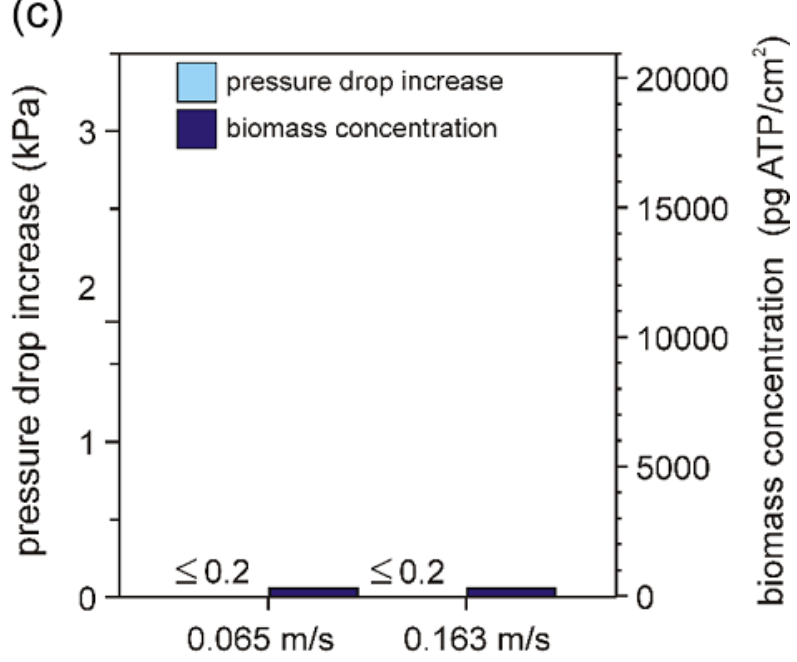

linear flow velocity

Fig. S7. Effect of linear flow velocity on pressure drop and biomass accumulation. (a) FCP with time over the monitor at a high and low linear flow velocity $(0.163$ and $0.065 \mathrm{~m} / \mathrm{s})$ before and after changing of the linear flow velocity on day 6 . The arrows indicate the effect of linear flow velocity change on the pressure drop. (b) FCP increase and accumulated biomass in the monitor after $6 \mathrm{~d}$ operation before and after reduction of the linear flow velocity and (c) before and after increasing the linear flow velocity. The FCP increase after adjustment of the linear flow velocity was calculated in comparison with FCP data determined at the same linear flow velocity prior to the experimental start [35]. 
(a)
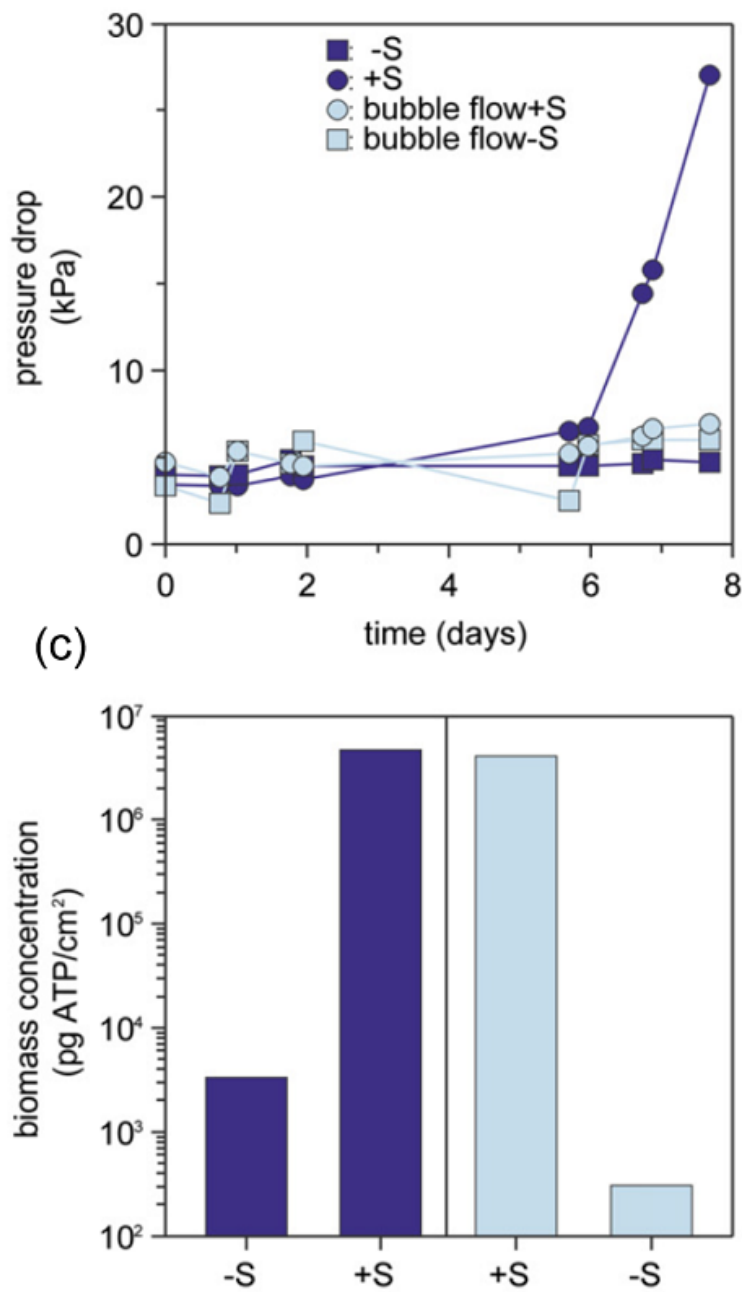

(e)

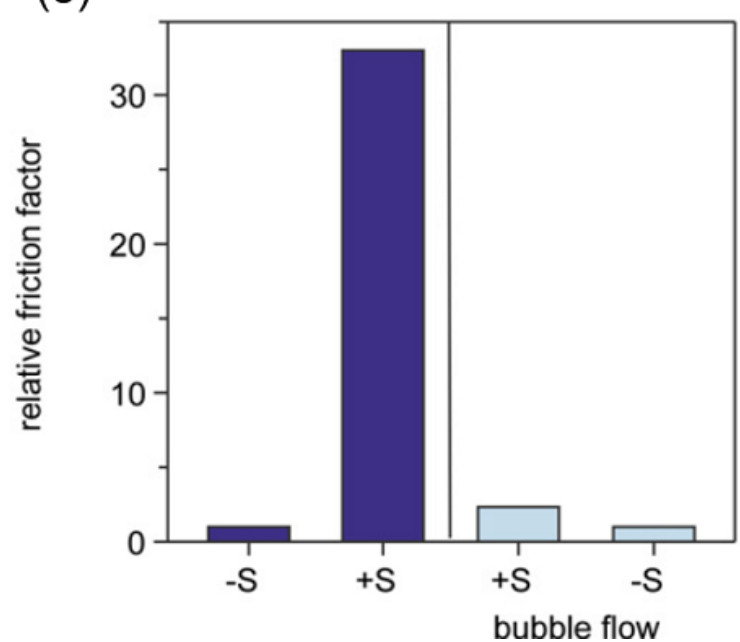

(b)
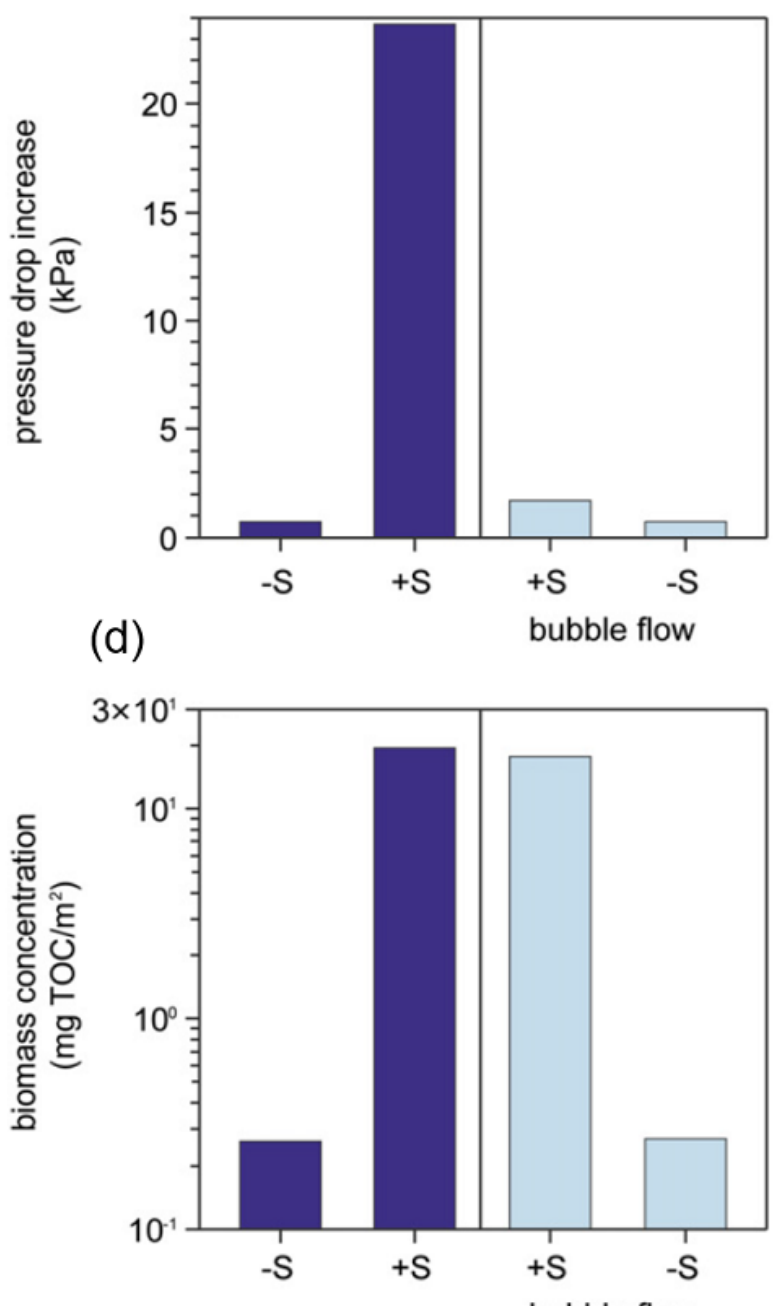

Fig. S8. Effect of bubble flow on pressure drop and biomass accumulation under the conditions with or without substrate. (a) FCP increase in time, (b) FCP increase, biomass concentration of (c) ATP and (d) TOC after 7.8 d MFS operation and (e) the relative friction factor. The monitors were operated with and without dosage of a biodegradable compound (200 $\mu$ g acetate C/L) to the feed water of the monitor without and with bubble flow. $-S=$ without bubble flow without substrate dosage; $+S=$ without bubble flow with substrate; bubble flow $+S=$ bubble flow with substrate; bubble flow $-S=$ bubble flow without substrate [34]. 


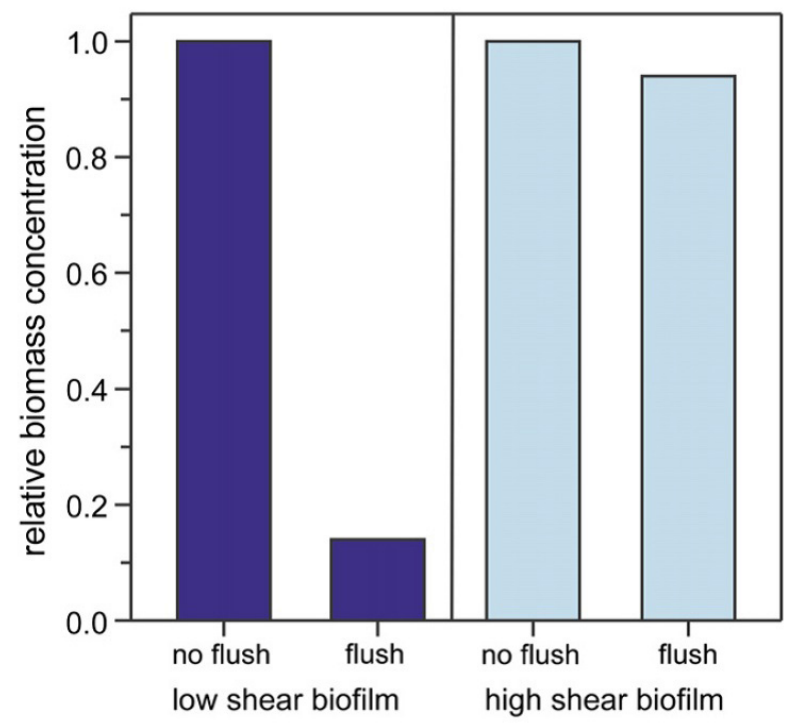

Fig. S9. Effect of flushing $(0.42 \mathrm{~m} / \mathrm{s})$ on biofouling developed at low and high linear flow velocity $(0.06$ and $0.31 \mathrm{~m} / \mathrm{s})[34]$.
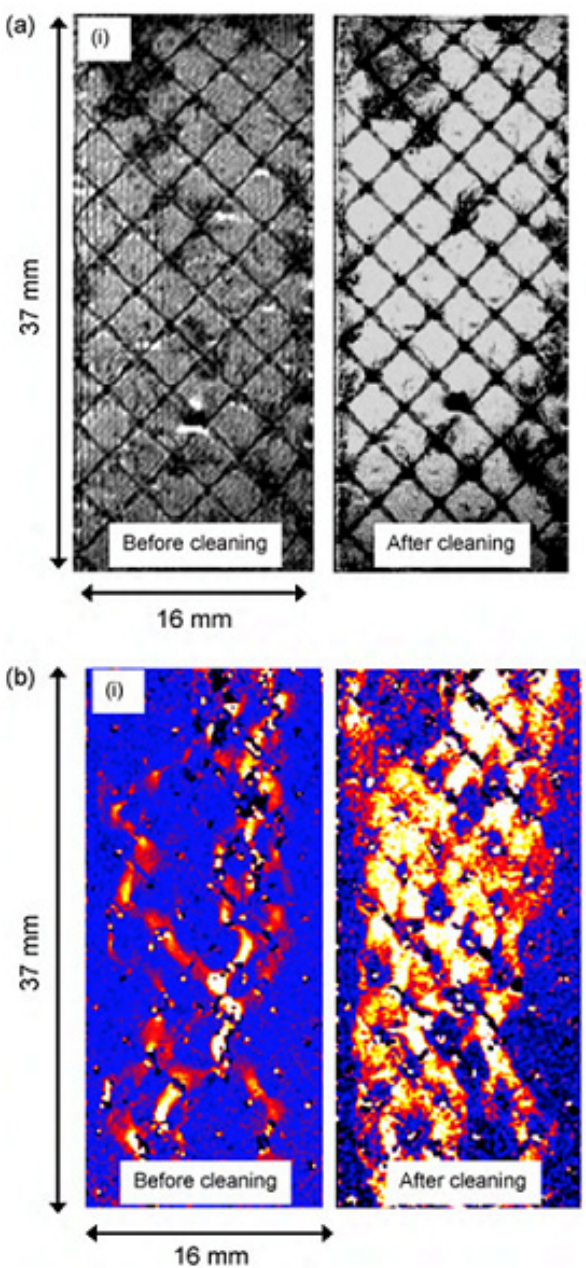

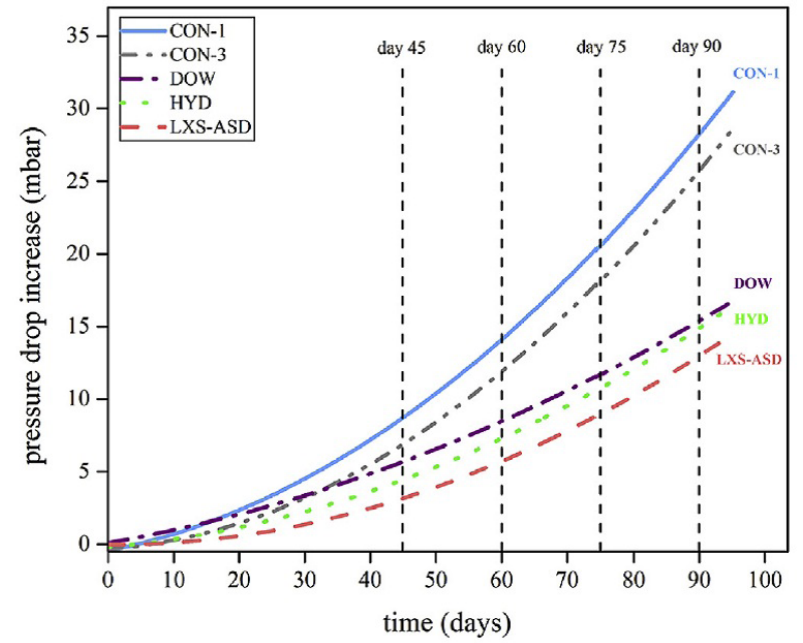

Fig. S10. FCP increase in MFSs containing two references and three modified feed spacers as a function of the running time at constant feed flow of $17 \mathrm{~L} / \mathrm{h}$ without nutrient dosage [44].
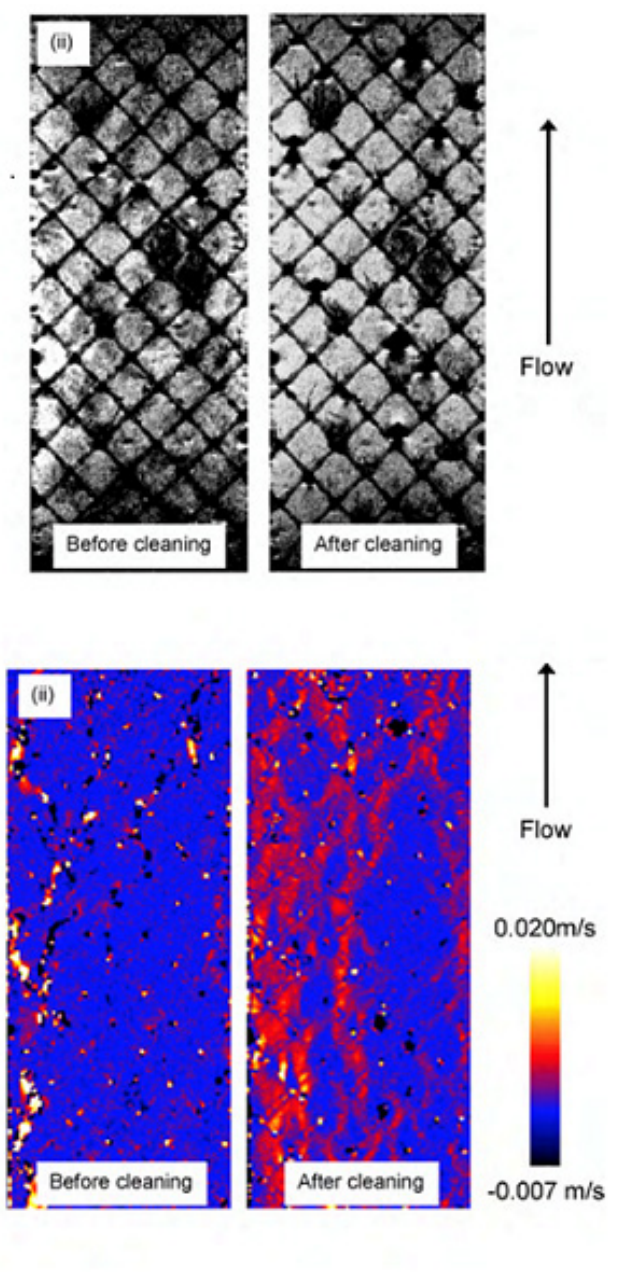

Fig. S11. Two-dimensional (a) structural and (b) velocity images for the MFSs fouled for (i) 1 week and (ii) 2 weeks, then cleaned using sodium hydroxide $(\mathrm{NaOH})[53]$. 

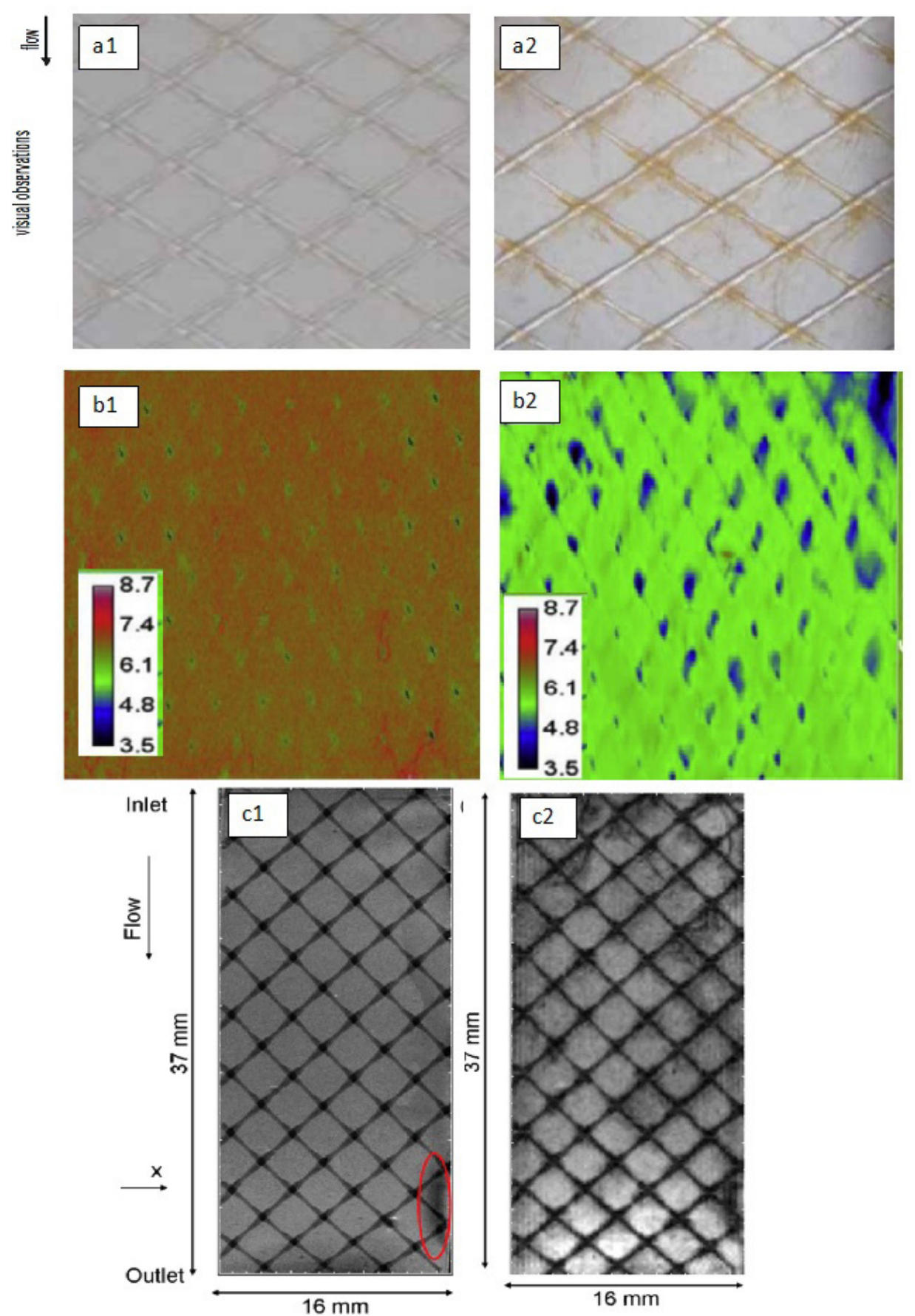

Fig. S12. In-situ visual observations of the feed spacer and membrane in the MFS (a) day 0 (a1) and day 6 (a2) [35]. Spatial distribution of oxygen concentration (mg/L) assessed during cross-flow operation at the inlet side of the MFS day 0 (b1) and day 5 (b2) [50]. Two-dimensional (2D) images of the flow cell for day 0 (c1) and day 4 (c2) The image resolution is $\sim 98 \mu \mathrm{m} / \mathrm{pixel}$ [53]. 
(a)

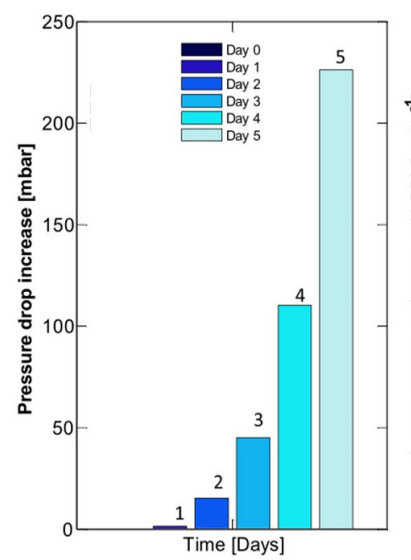

(b)

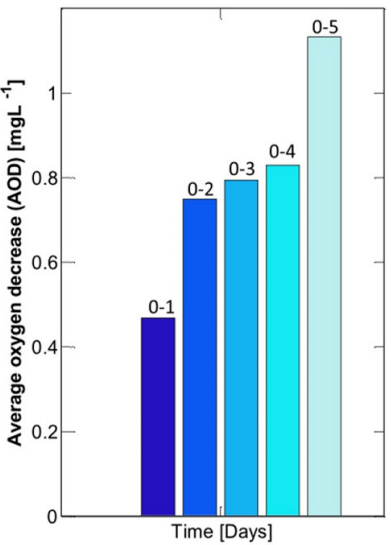

Fig. S13. Comparison of early biofouling detection potential between pressure drop development with time and oxygen decrease under cross-flow conditions. (a) FCP increase, (b) average oxygen concentration decrease (AOD) with time at constant cross-flow operation of the MFS [50].

(a)

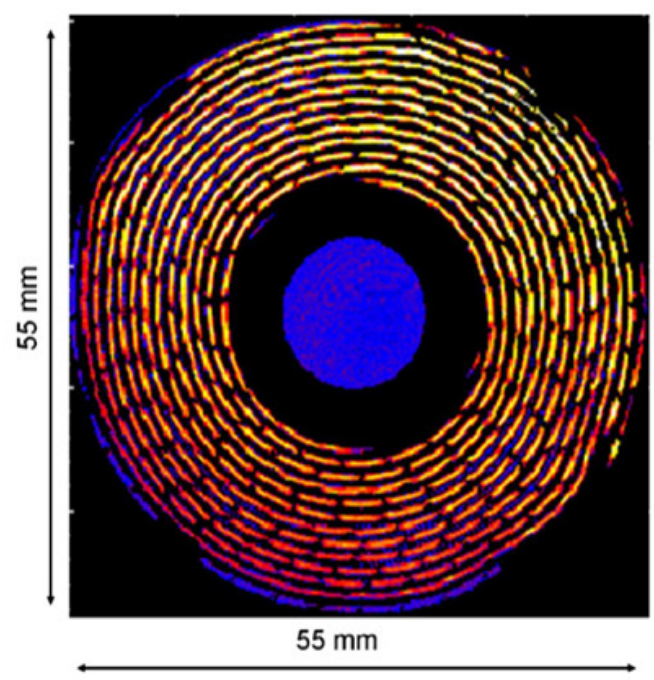

(b)

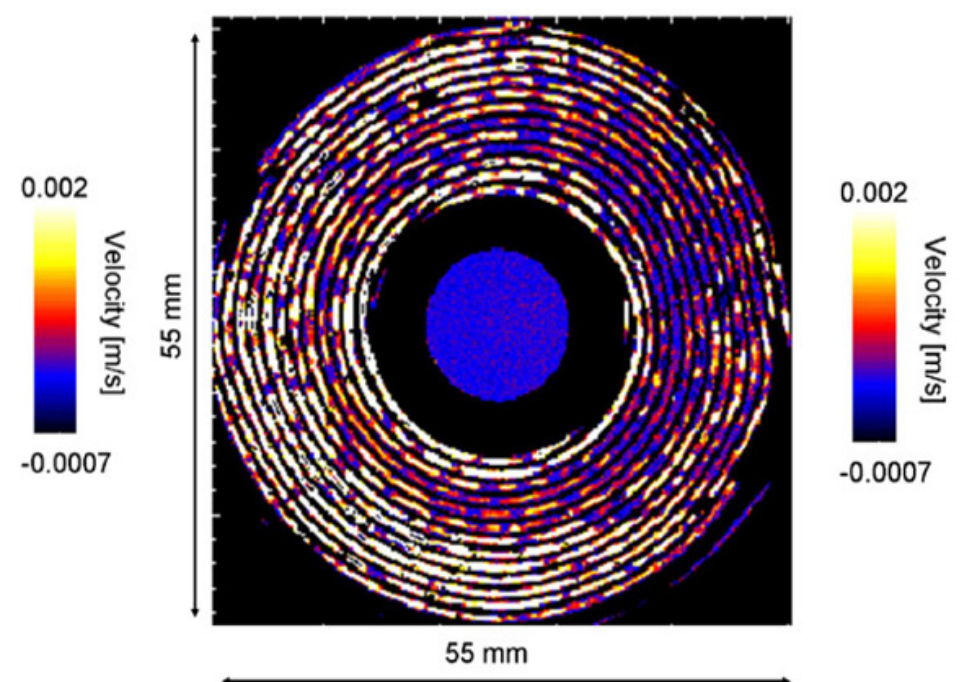

Fig. S14. Two-dimensional radial $(x-y)$ velocity images of the membrane module before (a) and after (b) biofouling. The image resolution is $\sim 220 \mu \mathrm{m} /$ pixel. The images show the superficial flow component ( $z$ component) on a color scale from $-0.0007 \mathrm{~m} / \mathrm{s}$ (black) to $0.002 \mathrm{~m} / \mathrm{s}$ (light yellow) [53]. 